\title{
Internal Derangements of the Temporomandibular Joint
}

\author{
Gary Warburton
}

\subsection{Introduction}

The term "internal derangement" has been used for more than a century in surgical and orthopedic literature to describe conditions that interfere with normal joint function $[1,2]$. In the knee, the term internal derangement is broadly used to describe a torn, ruptured, or deranged meniscus of the knee, a partial or complete cruciate rupture, with or without injury to the capsular ligament of the knee, resulting in ongoing or intermittent signs and symptoms such as pain, instability, or abnormal mobility. Alterations in the disc, condyle-fossa relationships in the temporomandibular joint (TMJ) were suspected as early as 1887 by Sir Astley Cooper and published by Annandale in the Lancet "on displacement of the inter-articular cartilage of the lower jaw, and its treatment by operation" [3]. The term internal derangement was adopted and used to describe disturbances between the articulating components of the TMJ, alluding to the damage to the internal structures and dysfunction of the joint associated with changes in the position of the disc $[4,5]$.

In the TMJ literature, the term has evolved to be synonymous with disc displacement. In the 1970s and 1980s, TMJ internal derangement was perceived as a mechanical problem and resulted in attempts to reposition or replace the disc. In 1979, McCarty and Farrar stressed on the relevance of disc displacement as a major disorder of the TMJ [5]. It was believed that a displaced or abnormal disc was a progressive problem that led to degenerative joint disease and as a result importance was given to repositioning the displaced disc. Conservative therapy was done by mandibular manipulations and oral appliances, and surgical repositioning was per-

Electronic Supplementary Material The online version of this chapter (https://doi.org/10.1007/978-981-15-1346-6_63) contains supplementary material, which is available to authorized users.

G. Warburton $(\bowtie)$

Department of Oral and Maxillofacial Surgery, University of

Maryland School of Dentistry, Baltimore, MD, USA

e-mail: gwarburton@umaryland.edu formed for patients who had persistent symptoms. A commonly performed surgical procedure was repositioning of the disc, and if the disc was perforated or beyond repair, even discectomy was performed. Various materials and tissues were used for disc replacement (cartilage, dermis, muscle fascia, fat, silastic, and Proplast-Teflon). However, the use of Proplast-Teflon resulted in severe destruction of the articular surfaces due to foreign body giant cell reactions [6-8].

Over the past few decades, there has been a conceptual shift from internal derangement and disc displacement being a primary diagnosis toward our current understanding that disc displacement/internal derangement is an endpoint and a manifestation of a process in which there is damage to articular tissues and biomechanical failure from a specific cause that must be identified if treatment is to be successful.

Clinical and basic science research has led us to the conclusion that internal derangement represents a variety of stages of biomechanical failure of the joint tissues, resulting from different causes.Wilkes staging system (Table 63.1) categorizes the extent of joint damage in internal derangement without being specific for the underlying cause that is responsible for the failure of the joint tissues. With this limitation in mind, Wilkes classification [9] is still useful today in communicating severity and guiding treatment.

The realization in the 1990s that arthroplasty with disc repositioning or discectomy often leads to degenerative joint disease and fibrosis, coupled with the fact that the disc repositioning was not reliably maintained, caused a major change in surgical management. Arthroscopic surgery of the TMJ was shown to be an effective alternative to arthroplasty. Arthroscopy was a reliable procedure to reduce the pain and to improve the maximal incisal opening without causing a change in position of the disc [10-15]. The role of disc displacement and disc position in symptomatic patients has been further questioned due to the fact that MRI studies have documented disc displacement in 32-38\% of asymptomatic patients and volunteers $[16,17]$. We now know that the abnormally positioned disc is not the primary cause on pain and dysfunction for many 


\section{Table 63.1 Wilkes classification}

\begin{tabular}{l|l}
$\begin{array}{l}\text { Stage I } \\
\text { Early }\end{array}$ & $\begin{array}{l}\text { Painless clicking } \\
\text { Anterior disc displacement with reduction }\end{array}$ \\
$\begin{array}{l}\text { Stage II } \\
\text { intermediate }\end{array}$ & $\begin{array}{l}\text { Clicking with intermittent pain and locking } \\
\text { Anterior disc displacement with reduction }\end{array}$ \\
$\begin{array}{l}\text { Stage III } \\
\text { Intermediate }\end{array}$ & $\begin{array}{l}\text { Pain, joint tenderness, frequent and prolonged } \\
\text { locking, restricted motion, } \\
\text { No degenerative changes } \\
\text { Anterior disc displacement with or without } \\
\text { reduction }\end{array}$ \\
\hline $\begin{array}{l}\text { Stage IV } \\
\text { Intermediate- } \\
\text { late }\end{array}$ & $\begin{array}{l}\text { Chronic pain, restricted motion, no clicking, } \\
\text { degenerative bony changes }\end{array}$ \\
Adhesions \\
Anterior disc displacement without reduction \\
Late & $\begin{array}{l}\text { Variable pain, painful function, reduced function, } \\
\text { crepitus, advanced } \\
\text { degenerative bony changes, gross disc deformity } \\
\text { and/or perforation Advanced adhesions } \\
\text { Anterior disc displacement without reduction }\end{array}$
\end{tabular}

patients as the majority of patients with displaced discs are asymptomatic through the process of adaptation.

Arthrocentesis was subsequently introduced as another effective yet minimally invasive means of treating patients with symptomatic internal derangement [18-22]. Arthroscopy and arthrocentesis allowed sampling synovial fluid and has been of tremendous value in our understanding of the biochemical mediators and cytokines responsible for inflammation, cartilage degeneration, and destruction of joint tissue leading to internal derangement [23-26].

Diagnostic criteria for temporomandibular disorders (TMD) for research and clinical purposes were recently updated in 2014 [27] and include internal derangement or disc displacement which is presented as:

- Disc displacement with reduction

- Disc displacement with reduction with intermittent locking

- Disc displacement without reduction with limited opening

- Disc displacement without reduction without limited opening

Normal disc position, displacement with reduction, and displacement without reduction are depicted in Fig. 63.1.

\subsection{Epidemiology}

Internal derangement of the TMJ is a relatively common problem. Farrar estimated that up to $25 \%$ of the population has TMJ internal derangement [28]. Epidemiologic studies have shown that TMJ clicking is detectable in up to $31 \%$ of the population, and crepitus is detectable in up to $40 \%$ of the population on auscultation, with a higher prevalence among women.

MRI studies have documented disc displacement in $32-38 \%$ of asymptomatic patients and volunteers $[15,16]$. The mean age for TMJ disorders is 34 with $90 \%$ of patients falling within 15-45 years of age range. Agerberg et al. studied 637 people aged 18-65 and found an incidence of $21 \%$ clicking in men and $28 \%$ in women, while crepitus was noted in $26 \%$ of men and $40 \%$ of women [29]. Disc displacement occurs most commonly in the anterior or anteromedial direction, which is the most common direction of displacement followed by lateral and rarely posterior displacement accounting for only $0.7 \%$ of displacements [30].

\subsection{Etiology}

Internal derangement is an endpoint and a manifestation of a process in which there is damage to articular tissues and biomechanical failure from a specific cause that must be identified if treatment is to be successful. The broad etiologic categories resulting in internal derangement are:

- Macrotrauma-major impact to jaw, e.g., sports injury, assault

- Microtrauma-parafunctional habits (clenching and bruxism)

- Systemic arthropathy-rheumatoid, SLE, psoriatic arthritis, HLA B27, infective, etc.

An alternative framework regarding etiology is:

- A normal joint subjected to overload (trauma or parafunction)

- An abnormal joint subjected to normal load (rheumatoid, SLE or psoriatic arthritis, osteochondroma, chondromatosis)

The majority of patients fall into the normal joint subjected to overload etiologic category and in particular due to parafunctional habits of clenching or bruxism during the day or at night.

Historically occlusion has been considered a primary etiologic factor, but this has now been refuted in current evidence-based literature [31, 32].

\subsection{Anatomy and Function Relevant to Internal Derangement}

The TMJ is a hinging and sliding synovial joint (ginglymoarthrodial joint) and forms the articulation between the mandibular condyle and the temporal bone. The articular surfaces 


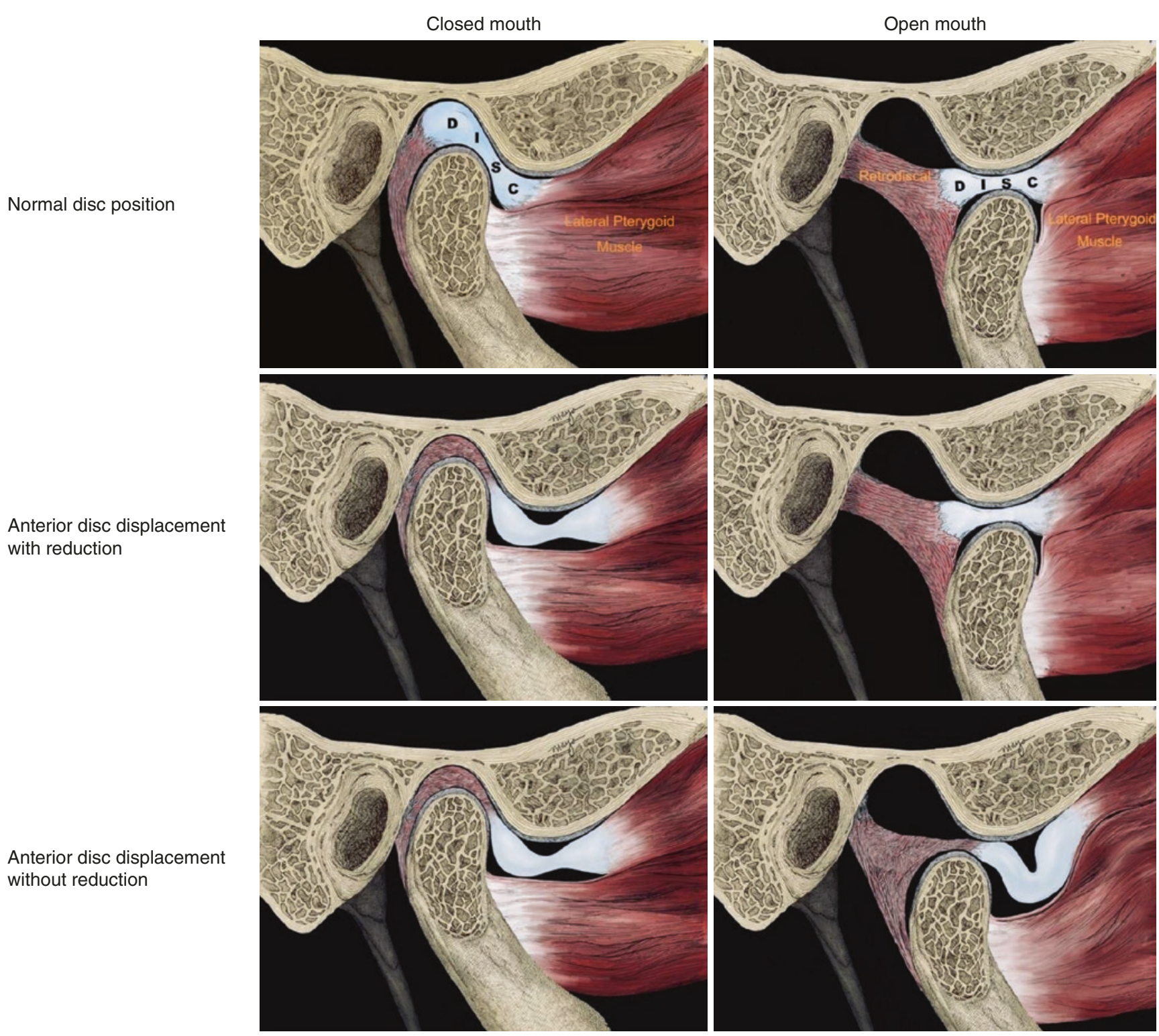

CAssociation of Oral and Maxillofacial Surgeons of India

Fig. 63.1 Normal and displaced disc positions, with and without reduction (modified with the permission of Dr. Robert Talley)

are covered with fibrocartilage, while most other synovial joints are composed of hyaline cartilage. Fibrocartilage is composed of fibrochondrocytes, fibroblast-like cells, type I collagen, and proteoglycans. Fibrocartilage is less susceptible to degeneration and also has a greater repair capacity compared to hyaline cartilage [33]. The articular disc or meniscus that is interposed between the mandibular condyle and articular eminence of the temporal bone is also a fibrocartilaginous structure in the shape of a biconcave elliptical disc. It has a thicker posterior and anterior band with a thinner intermediate zone in between (Fig. 63.2). From a lateral viewpoint in the closed mouth position when the condyle is seated in the glenoid fossa, the posterior band is normally positioned at the $12 \mathrm{o}$ 'clock position from a point in the cen- ter of the condyle. As the condyle rotates and translates forward beneath the disc during mouth opening, the disc comes to lie above the condyle (this has been termed "roofing"). The disc itself is an avascular structure and that has no innervation. The metabolic and nutritional requirements of the avascular disc are provided by the surrounding synovial fluid through a process known as weeping lubrication (whereby a small amount of synovial fluid is forced into and out of the disc during the compressive forces generated by joint function and loading of the disc). The disc is anchored to the medial and lateral poles of the condyle by the collateral (discal) ligaments (Fig. 63.3).

Figure 63.4 shows the attachments of the disc in a sagittal view. The posterior attachment of the disc is the retrodiscal 

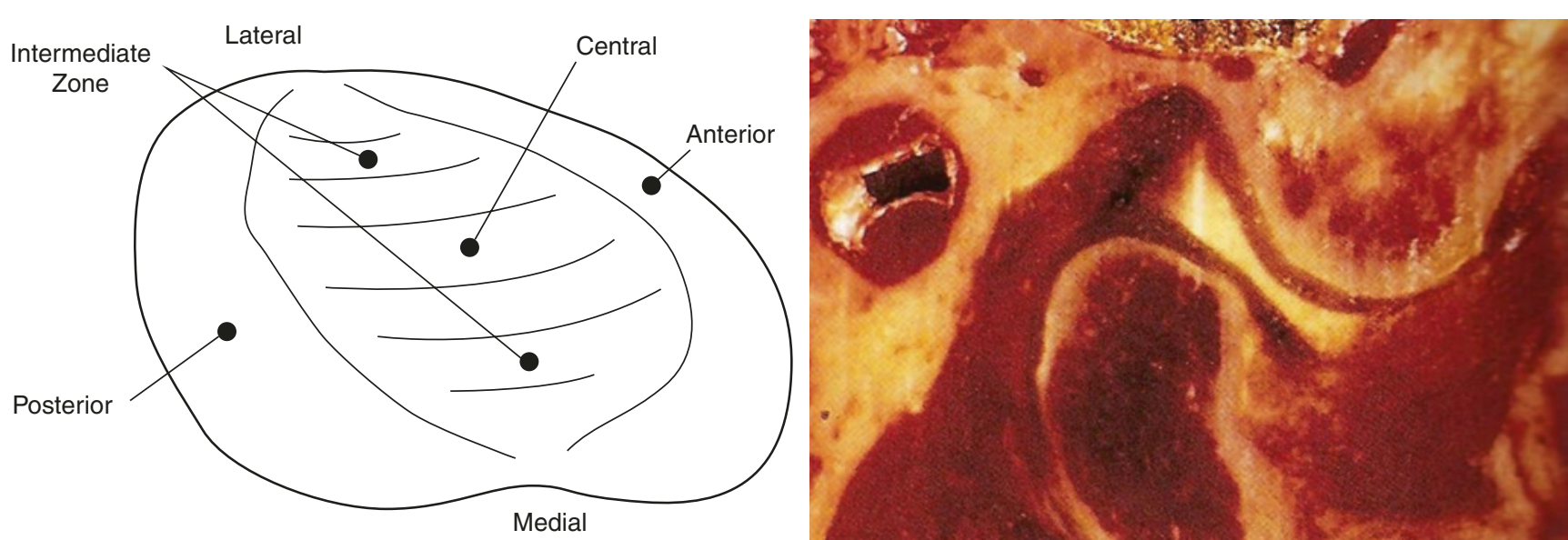

CAssociation of Oral and Maxillofacial Surgeons of India

Fig. 63.2 Articular disc or meniscus (normal position) (Also see normal disc position in open mouth and closed position in Fig. 63.1)

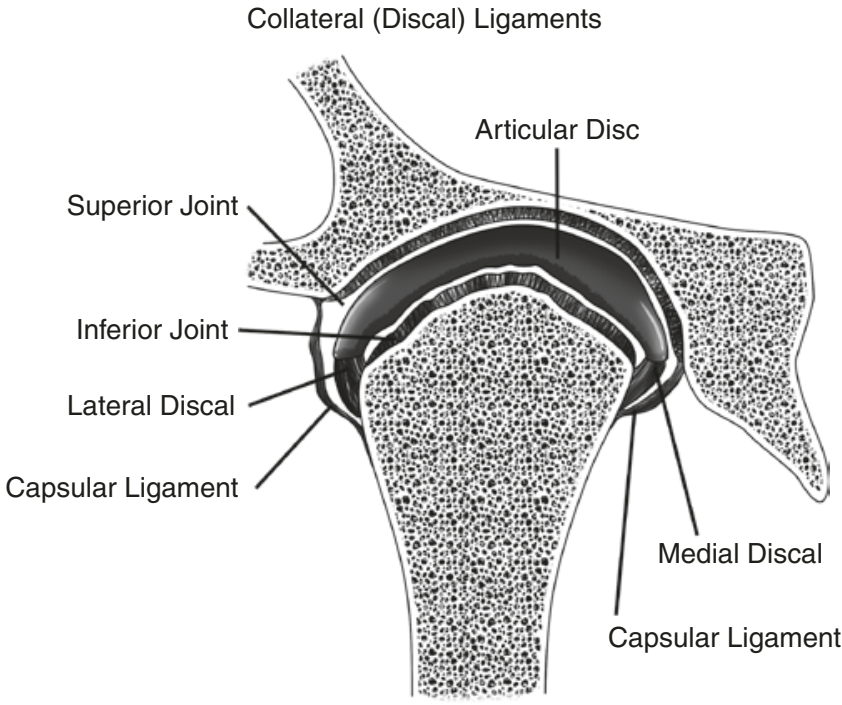

CAssociation of Oral and Maxillofacial Surgeons of India

Fig. 63.3 Coronal view of the medial and lateral collateral (discal) ligaments

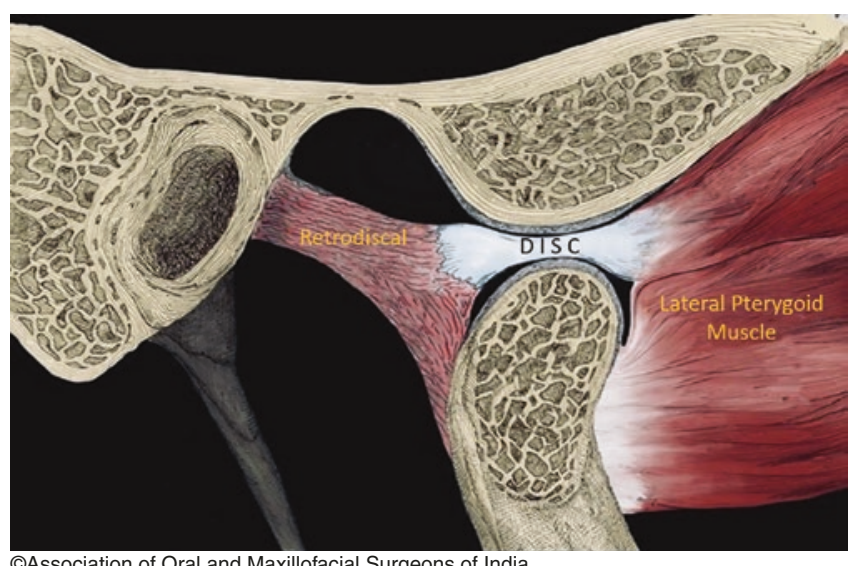

(OAssociation of Oral and Maxillofacial Surgeons of India

Fig. 63.4 Attachments of the disc in a sagittal view (modified with the permission of Dr. Robert Talley) tissue. The retrodiscal tissue is a bilaminar structure with a superior lamina, inferior lamina, and intervening loose connective tissue that is very vascular and well-innervated. The retrodiscal attachment connects the disc to the tympanic plate of the temporal bone by the superior lamina, which is composed of connective tissue and elastic fibers. These elastic fibers condense to form a prominence recognized arthroscopically as the posterior oblique protuberance/band. The inferior lamina is composed of collagen fibers and inserts into the condylar neck. The disc and retrodiscal tissue together divide the TMJ into upper and lower joint spaces which are filled with synovial fluid. The anterior attachment of the disc is to the temporal bone, the anterior condylar neck, and the upper head of the lateral pterygoid muscle, while the medial and lateral attachments are to the capsular ligaments as well as the collateral ligaments. All the joint surfaces are covered with synovial lining except the disc itself, glenoid fossa, articular eminence, and condylar head.

It is the collateral (discal) ligaments along with the superior and inferior lamina of the retrodiscal tissue that are disrupted and elongated when the disc is displaced anteriorly in internal derangement.

The glenoid fossa of the temporal bone lies immediately beneath the middle cranial fossa (Fig. 63.5a, b). From both arthroscopic and open surgical standpoints, one must recognize that the bony roof of the fossa is extremely thin. An autopsy study revealed that the glenoid fossa was only $0.2-$ $1.5 \mathrm{~mm}$ thick in normal joints and $0.5-2.0 \mathrm{~mm}$ thick in joints with disc displacement [34]. Care must be taken not to perforate the thin roof of the fossa during arthroscopic and open TMJ surgical procedures.

The TMJ is innervated by the trigeminal nerve, predominantly through the auriculotemporal branch of the mandibular division which passes behind the condylar neck and penetrates the capsule to enter the joint. However, some innervation also comes from the deep temporal and masseteric branches. 

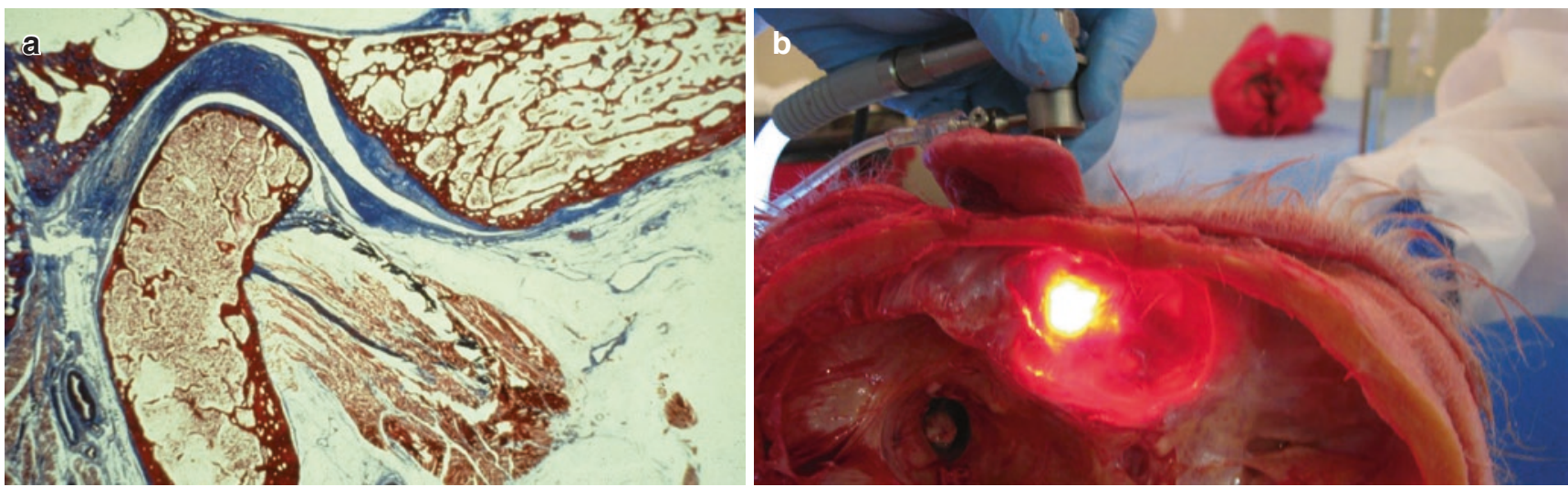

CAssociation of Oral and Maxillofacial Surgeons of India

Fig.63.5 (a) Sagittal section through TMJ and glenoid fossa. (b) Cadaveric specimen viewed from the middle cranial fossa (brain removed) with an arthroscope in the left TMJ. Both demonstrate the thin roof of the glenoid fossa

\subsection{Clinical Features and Diagnosis}

The most common presenting complaints in patients with TMJ internal derangement include:

Pain

Joint noises (click or crepitation)

Loss of function

Occasionally a change in occlusion

The loss of function may be due to limited mouth opening (closed lock in anterior disc displacement without reduction), a mechanically obstructive click, or dietary compromise secondary to pain.

\subsubsection{Patient History}

A good clinical history is essential for accurate diagnosis of any TMJ disorder including internal derangement. Questions including onset and evolution of the problem may reveal a classical story of a clicking or "popping" joint, indicating a disc displacement with reduction, or a story in which a patient with a history of a clicking joint notices that the click suddenly disappears and at the same time develops limited mouth opening and pain indicative of progression to disc displacement without reduction. Questions regarding initiating factors are helpful in identifying the underlying etiology (trauma or parafunction). Patient reports of pain increasing with stress or pain present on waking from sleep are strongly suggestive of parafunctional habits.

The answers to these pain questions may suggest pain originating from the joint when the pain is localized over the preauricular area, compared to muscular pain when it is more
Other questions should include details of prior treatment attempts and specific questions regarding pain:

Location

Radiation

Severity

Timing (intermittent or constant)

Duration and frequency of episodes

Exacerbating factors

Relieving factors

Associated symptoms (headache, tinnitus, etc.)

widespread, a critical differentiation in determining appropriate management. Problems with other joints such as pain or laxity may suggest systemic arthritis or even conditions such as Ehlers-Danlos syndrome.

\subsubsection{Patient Examination (Fig. 63.6a-c)}

Should include examination of the muscles of mastication, TMJ, range of mandibular motion, and intraoral examination to evaluate occlusion and signs of parafunction (buccal mucosal ridging at the level of the occlusal plane, scalloping of the lateral border of the tongue, tooth wear, and fractured teeth or restorations).

When examining each pair of muscles, one should evaluate for tenderness, trigger points, muscle mass, and tone. If the patient reports pain on palpation (indicating myalgia), it is helpful to determine if the pain is localized to the point of palpation (local myalgia), spreading beyond the point of palpation but within the muscle boundary (myofascial pain), or radiates outside the muscle boundary (myofascial pain with referral). 

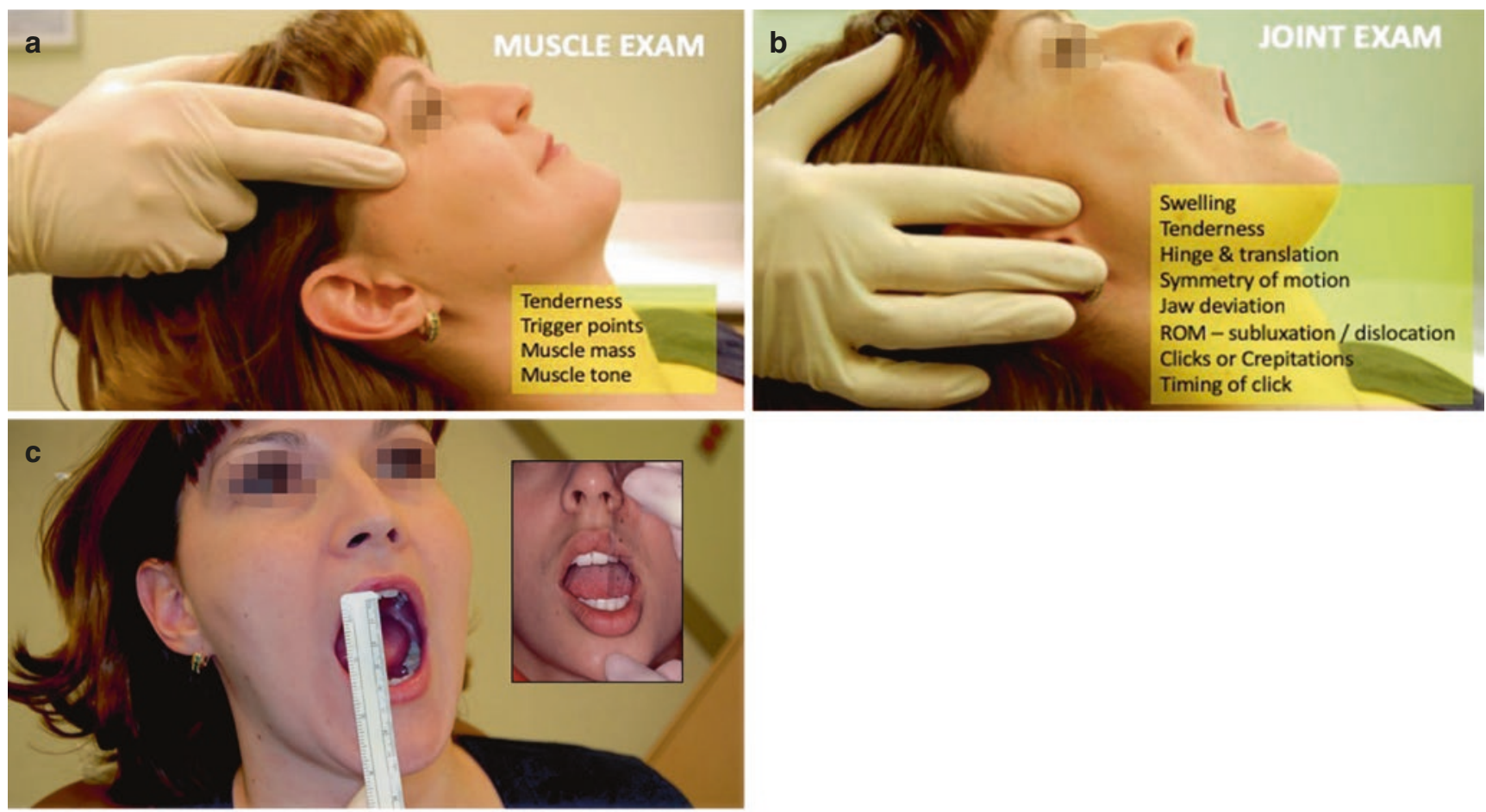

CAssociation of Oral and Maxillofacial Surgeons of India

Fig.63.6 (a-c) Examination of muscles, joint, and range of motion

Fig. 63.7 Anterior disc displacement and retrodiscitis (as seen in the inset arthroscopic image) with a positive direct pressure loading test of the right $\mathrm{TMJ}=$ biting on tongue blades between left canines loads the right TMJ, and pain is reported in the right TMJ

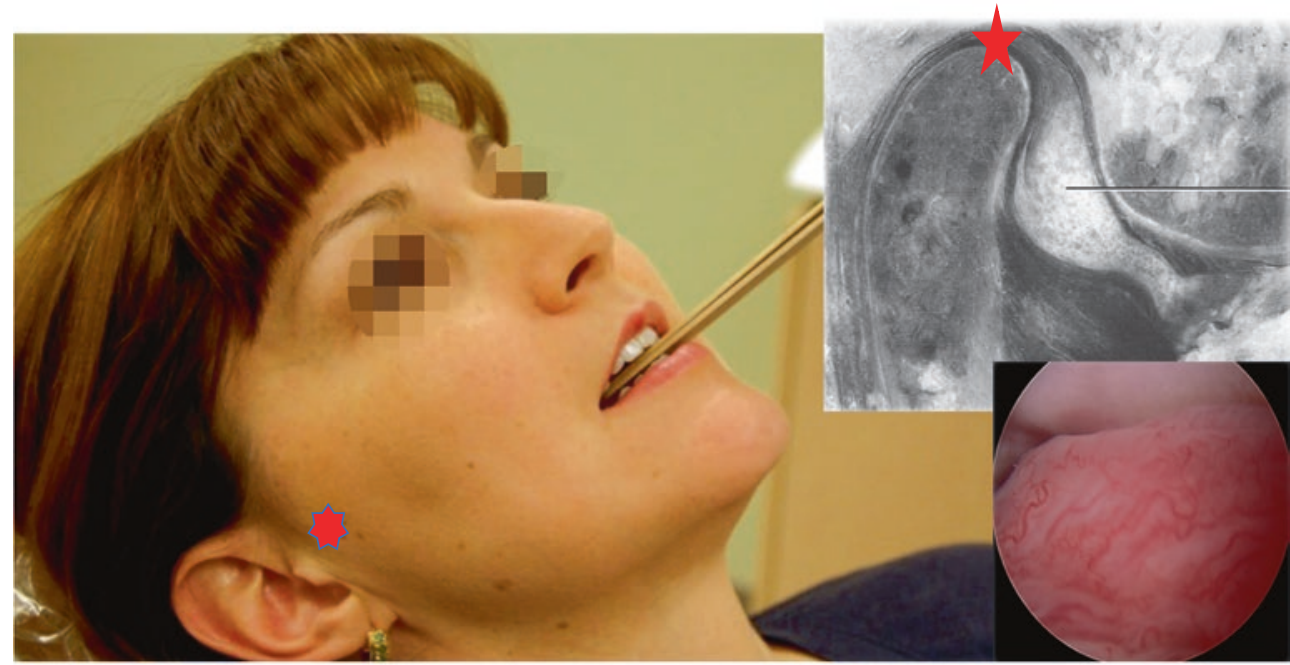

(C)Association of Oral and Maxillofacial Surgeons of India
When examining the joint, one should evaluate for tenderness, swelling, range of motion (hinge and translation), symmetry of motion or deviations, subluxation/dislocation, clicks, and crepitation. Joint noises may be audible or palpable, but some may only be detected by auscultation. Timing of any opening click provides clinical information on the extent of disc displacement before reduction. A very early click on condylar translation suggests minimal anterior disc displacement before reduction, while a late click suggests greater anterior displacement of the disc. If the disc is anteriorly displaced, there may be significant retrodiscitis due to the condyle functioning on the retrodiscal tissue rather than the disc itself (Fig. 63.7). If the patient is asked to bite on two wooden tongue blades between the canine teeth and they report pain localized to the contralateral TMJ that is now being loaded, this is pathognomonic for retrodiscitis and is known as a positive direct pressure loading test. Crepitations often indicate perforation, usually in the retrodiscal tissues, and may occur due to long-term function on the retrodiscal tissue or trauma. 


\subsubsection{Radiographic Evaluation}

While plain radiographs and $\mathrm{CT}$ scans are useful for evaluating bony changes, MRI scans are best suited for evaluating disc position and displacement and have a diagnostic accuracy of at least $90 \%$ [35]. MRI should be ordered with both $\mathrm{T} 1$ and $\mathrm{T} 2$ images in the open and closed mouth positions
(Fig. 63.8a-c); often additional imaging sequences are helpful such as fat suppressed or STIR sequences which help to show edema in tissues that contain fat. This can be helpful in evaluating edema in the cancellous bone of the condylar head. Using MRI, one can assess the bone of the condyle, fossa, and eminence (looking for sclerosis, erosions, flattening, osteophytes, and breaks in cortical continuity), the disc
T1 Closed

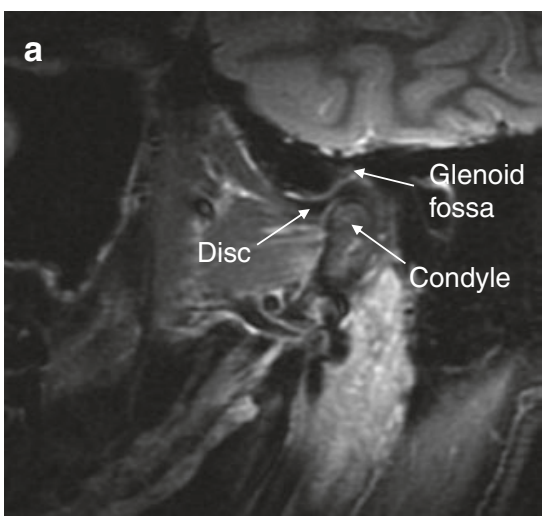

T1 Closed
T1 Open

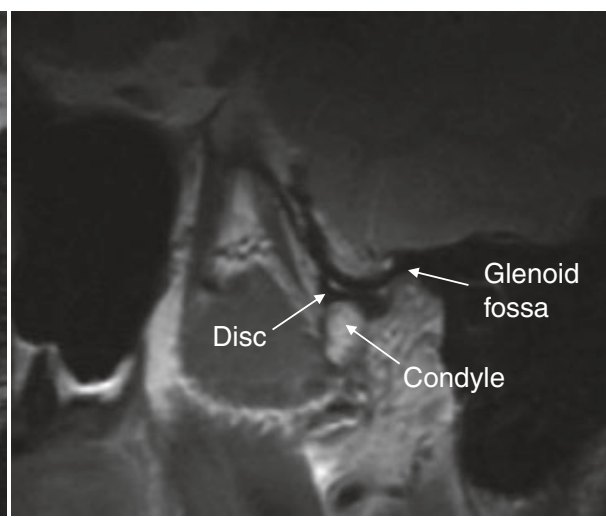

T1 Open

T2

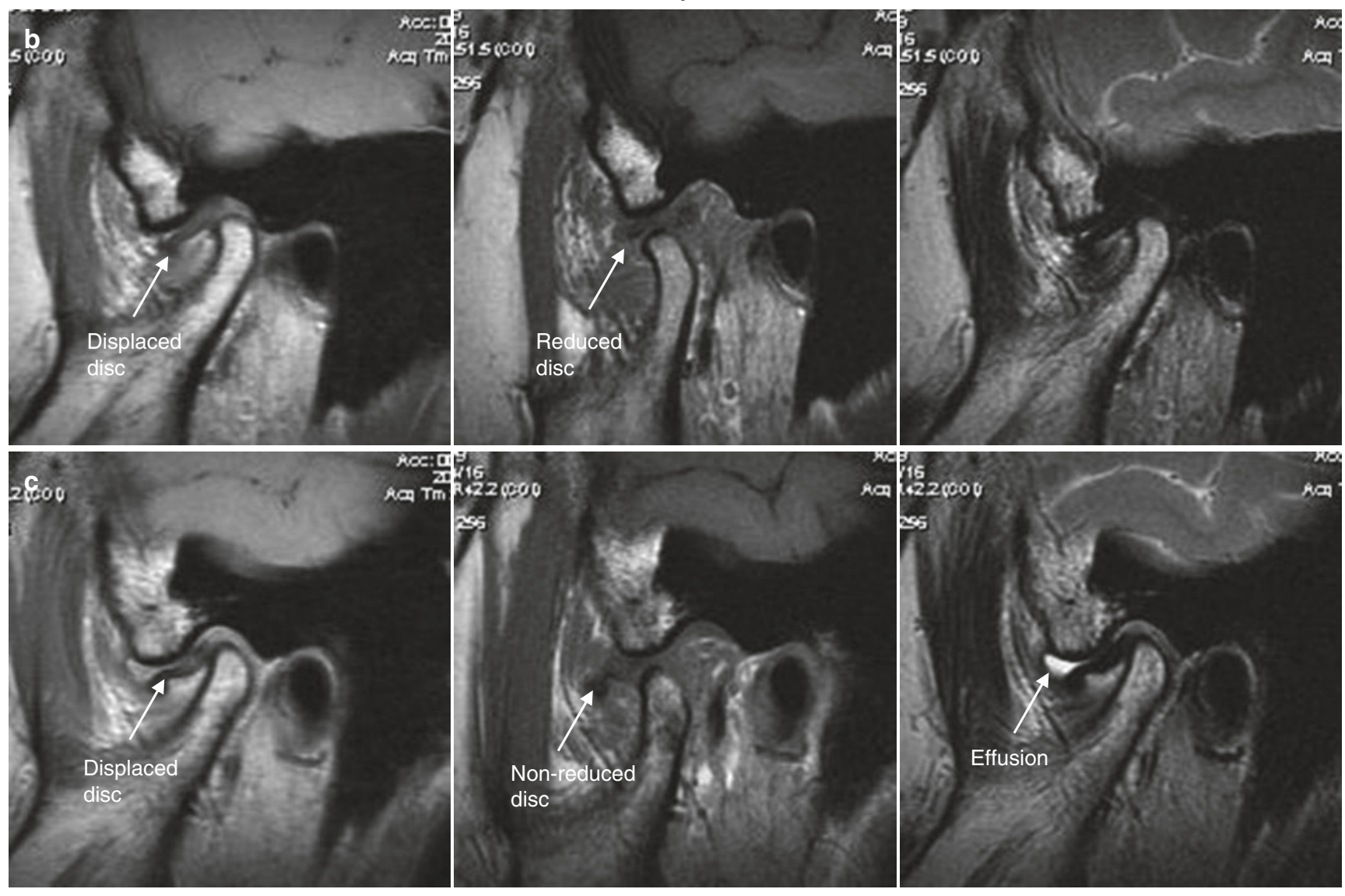

CAssociation of Oral and Maxillofacial Surgeons of India

Fig. 63.8 (a-c) MRI scan-T1 and T2 images in closed and open mouth positions. (a) Normal disc position. (b) Anterior disc displacement with reduction. (c) Anterior disc displacement without reduction and superior joint space effusion 
(looking at its position, density, shape, size, and continuity in cases of perforation), effusions which are easily seen on T2 sequences, and finally for collapse of the joint space. The sagittal closed and open mouth images determine if the disc is displaced and whether or not it reduces on opening.

\subsubsection{Serology}

Is helpful in the diagnosis of primary inflammatory arthritis (Table 63.2). Rheumatoid factors (RFs) occur in 60-80\% of patients with rheumatoid arthritis (RA) [36]. While they are sensitive, their diagnostic utility is limited by their relatively poor specificity, since they are also found in 5-10\% of healthy individuals, 20-30\% of people with SLE, virtually all patients with mixed cryoglobulinemia (usually caused by hepatitis $\mathrm{C}$ virus infections), and those with many other inflammatory conditions. Higher titers of RFs (at least three times the upper limit of normal) have somewhat greater specificity for RA. The prevalence of RF positivity in healthy individuals rises with age. More recently, other antibody markers have been utilized. Anti-cyclic citrullinated peptide (anti-CCP) antibodies have a similar sensitivity to RF for RA but have a much higher specificity (95-98\%). Anti-CCP antibodies are also present early in the disease, and their presence often correlates with more severe forms of RA, making them better prognostic indicators [37]. HLA-B27 is associated with seronegative spondyloarthropathies, psoriatic and reactive arthritis [38].

Table 63.2 Serology in primary inflammatory arthritis

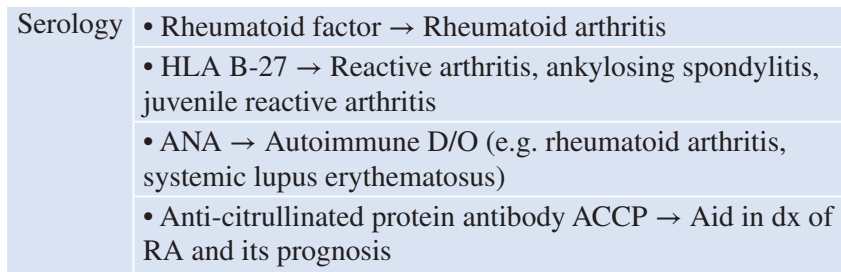

\subsubsection{Diagnostic Local Anesthetic Block}

In complex cases where history and examination fail to clearly confirm pain originating from the joint itself, or in cases that have undergone previous surgeries on the TMJ, or in chronic pain patients, an auriculotemporal nerve block and injection of local anesthetic into the superior joint space is very helpful and can demonstrate the amount of pain originating from the joint. The author uses 3\% mepivacaine injected using a dental syringe (Fig. 63.9a-c). With the patient in occlusion, the needle is inserted and advanced to contact the posterior condylar neck where half the carpule is injected as an auriculotemporal nerve block. The patient then opens their mouth, and the needle is advanced superiorly to contact the posterior slope of the articular eminence, and the remaining anesthetic is deposited into the superior joint space. The patients pain score before is compared to the pain score 10-15 min after injection. Any portion of pain that has resolved is most likely originating from the joint. This is helpful in determining if surgery is indicated and also in providing realistic postoperative pain expectations for the surgical patient.

\subsection{Treatment of Internal Derangement}

Treatment for internal derangement can be divided into nonsurgical and surgical options, but the general treatment goals are the same:

Decrease joint overload

Decrease pain

Reduce inflammation

Improvement in the range of motion

Restore function

Causative factors to be identified and controlled 

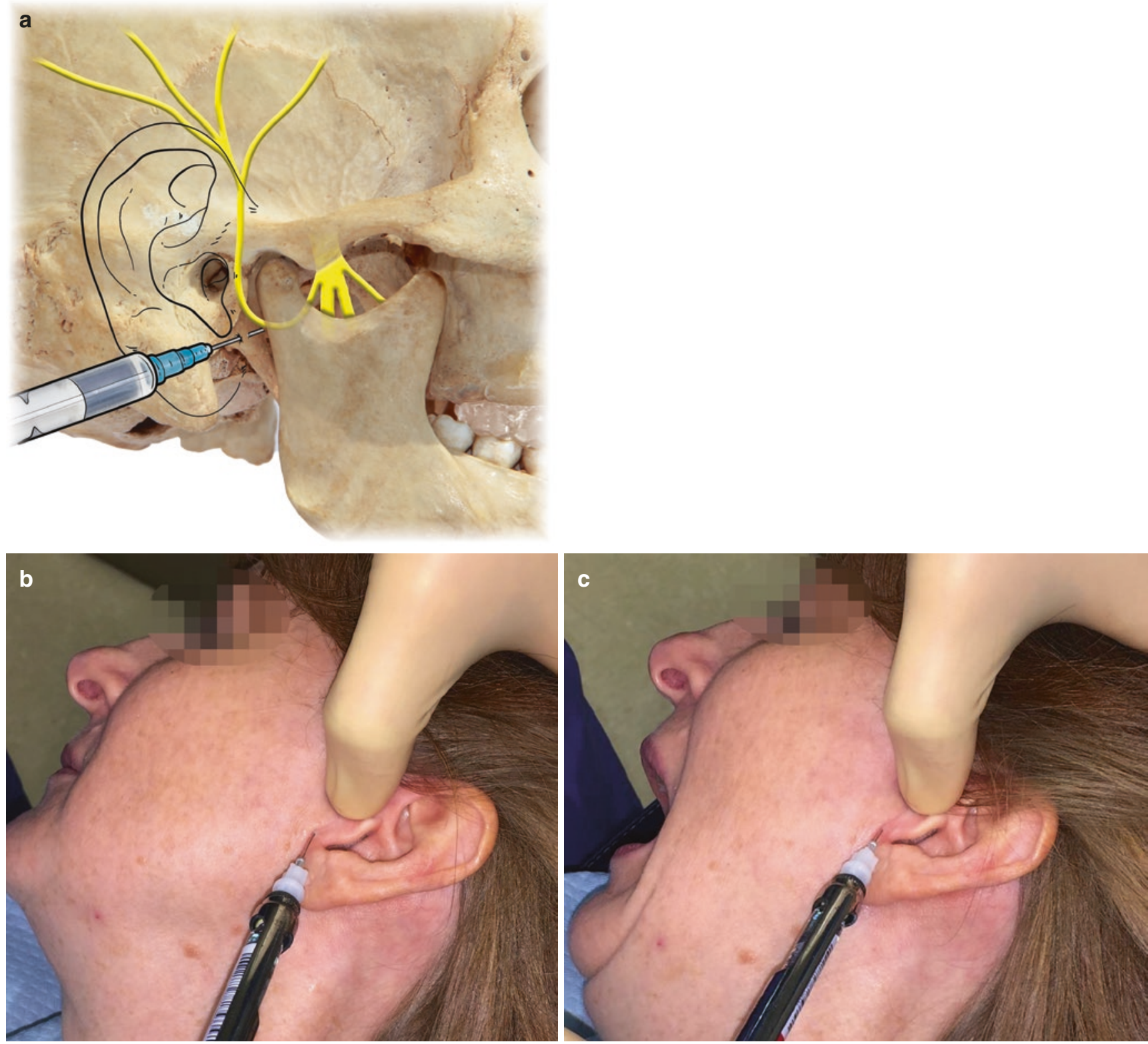

CAssociation of Oral and Maxillofacial Surgeons of India

Fig. 63.9 (a-c) Diagnostic auriculotemporal nerve block and TMJ injection

Clinical research [39-41] into the natural progression of TMJ internal derangement has shown:

- Without any treatment, improvement is seen in many patients.

- On an average, about 1 year is required for the resolution of symptoms, but this time is variable.
- About $25-33 \%$ of patients do not improve.

- Older patients and those with MRI evidence of more advanced disease (osteoarthritis and advanced internal derangement) are at higher risk for not improving spontaneously. 


\subsubsection{Nonsurgical Treatment}

Nonsurgical options include:

Patient education

Soft diet

Occlusal appliance/orthotic devices

Parafunctional habit awareness

Biofeedback

Nonsteroidal anti-inflammatory medication

Muscle relaxants

Botulinum toxin

Physical therapy

Occasionally, psychology referral and counselling are indicated in certain patients.

Patient education is of great value. A simple explanation of the mechanics causing a clicking joint with internal derangement with the information that around $30 \%$ of the population have internal derangement can be very reassuring and put a patient's mind at ease. Furthermore, educating the patient in habit awareness to avoid daytime clenching is a key element in the long-term success of any nonsurgical or surgical treatment (Table 63.3).

Orthotic devices or occlusal appliances may help to reduce nighttime parafunctional habits. However, our understanding of orthotic devices has changed significantly over time. In the late 1930s and 1940s, temporomandibular joint disorders (TMD) used to be seen as problems related to occlusal or skeletal disharmony. Costen was an otolaryngol-

Table 63.3 Nonsurgical management

Patient education (explain the condition)
Patient home care instructions
- Soft diet
- Awareness and avoid clenching habits
- Night time bruxism—night guard/orthotic
- Range of motion
Pharmacotherapy
• NSAIDs, muscle relaxants, tricyclics, sedatives, Botox
Occlusal appliance/orthotic
- For nighttime parafunctional habits
Physical therapy
• Posture training
- Mobilization/manipulation/joint distraction
- Massage/muscle conditioning
- Physical agents or modalities
- TENS, ultrasound, iontophoresis, phonophoresis,
electrogalvanic stimulation, thermal
Stress reduction
• Psychologist
• Counselor
- Psychiatrist

ogist who in 1934 first suggested the link between occlusion, TMJ disorders, and ear symptoms based on his observations in 11 patients [42]. This evolved into orthotics and occlusal therapies being used for the treatment of TMJ disorders in the 1940 s and 1950s. However, a significant paradigm shift has occurred as the classic dental and skeletal etiologic theories have been challenged and refuted by studies conducted around the world, and a biopsychosocial medical model of orthopedics, pain phenomenology, and behavioral factors has gradually replaced them. As a result, the conceptual basis for occlusal appliances/orthotic use has significantly changed over the years. Occlusal appliances/orthotics were initially conceived and used based on these old dental and skeletal etiologies and were thought to produce occlusal disengagement, relax jaw musculature, restore vertical dimension of occlusion, unload the joint(s), or reposition the condyle and or disc. Even today, these are often described as deprogrammers or jaw-repositioning devices that can establish ideal craniomandibular relationships wile relieving pain and restoring function. Until the 1960s, there were no wellcontrolled, well-designed, systematic studies evaluating the treatment of TMD. Instead, there were a number of anecdotal reports claiming success with various mechano-dental treatments, including various designs of oral appliance or orthotic [43, 44]. As the evidence-based literature has evolved, these reports have been refuted. Lundh [45] divided patients with symptomatic TMJ disc displacement into two treatment groups: one group with no treatment and one group with an occlusal appliance/orthotic and compared outcomes. After 12 months, pain had resolved in around $33 \%$ of patients in both groups. $40 \%$ of patients reported increased pain in the occlusal appliance/orthotic group compared to $16 \%$ in the no treatment group. Truelove [46] evaluated 200 patients with anterior disc displacement with reduction, arthralgia, and myalgia who were randomly assigned into three treatment groups: group 1 had basic nonsurgical treatment (education, self-care, hot/cold packs, and passive stretching), group 2 had hard flat plane occlusal appliance/orthotic, and group 3 had soft splint. Outcomes were evaluated after 3 and 12 months, and there were no significant differences in success among the three groups. Greene [47] and Laskin [48] studied the placebo effect using mock/sham occlusal appliances and sham occlusal adjustments. They found that nonoccluding appliances/orthotics helped over $40 \%$ of patients and mock/sham occlusal adjustments helped almost twothirds of patients. Furthermore, the use of occlusal appliances/orthotics may increase the parafunctional habit in some resulting in a patient complaining of increased pain and/or stiffness after use. In addition, partial coverage devices may result in occlusal changes if used for more than a few months due to eruption of teeth. Therefore, our perception of occlusal appliances/orthotics must take into consideration the current evidence-based literature. 
In review of evidence-based literature on occlusal appliance/orthotics [45-47, 49, 50], we can conclude:

- Symptoms of myalgia and arthralgia may be decreased by occlusal appliances.

- Wear on the dentition caused by parafunctional habits may be reduced.

- Risk is low if they are not worn $24 \mathrm{~h}$ a day.

- The disc position is not changed by the appliance.

- Over time, many patients show improvement in signs and symptoms.

- There is no appreciable significant difference between the nontreatment and treatment group.

- Palliative care (NSAIDs, education, diet modification, exercises) seem to be as effective as more expensive appliance therapy.

- All treatments have a powerful placebo effect.

In Klasser's review [50] of occlusal appliances/orthotics, he concludes that rather than trying to establish new horizontal or vertical jaw relationships, occlusal appliance/orthotics today should be viewed as "oromandibular crutches," which are analogous to back braces or ankle support orthotics because they support the joint and provide symptomatic relief while the joints are recovering. Table 63.4 outlines Klasser's conclusions on occlusal appliance use and limitations.

Most often, painful internal derangement causes a reactive muscle response. This muscle response and myalgia can be treated by soft diet, heat, and massage to the affected muscles, limiting the range of motion to within the pain-free range, NSAIDs, muscle relaxants, physical therapy, and even botulinum toxin injections (e.g., Botox).

Table 63.4 Occlusal appliance/orthotic device limitations [50]

\begin{tabular}{|c|c|}
\hline Can do & Can't do \\
\hline $\begin{array}{l}\text { - Protect teeth/restorations from } \\
\text { fracture due to bruxism/clenching } \\
\text { - Reduce/change the loading of the } \\
\text { TMJ by reducing intensity, } \\
\text { frequency, and duration of bruxism/ } \\
\text { clenching } \\
\text { - Adding a foreign body into the } \\
\text { occlusion briefly reduces muscle } \\
\text { activity } \\
\text { - Reduce headaches related to } \\
\text { bruxism/clenching } \\
\text { - Reduce internal derangement } \\
\text { symptoms related to bruxism/ } \\
\text { clenching upon awakening } \\
\text { - Change the neuromuscular engrams } \\
\text { deprogramming }\end{array}$ & $\begin{array}{l}\text { - Unload the disc by pivoting } \\
\text { the mandible on the molars } \\
\text { and distracting the condyle } \\
\text { - Retrain muscle to be less } \\
\text { active upon cessation of the } \\
\text { appliance } \\
\text { - Recapture and reposition } \\
\text { discs } \\
\text { - Permanently reduce } \\
\text { bruxism/clenching } \\
\text { - Relieve headaches that are } \\
\text { neurovascular or vascular in } \\
\text { origin }\end{array}$ \\
\hline
\end{tabular}

\subsubsection{Surgical Treatment (Fig. 63.10)}

The vast majority (approximately 90\%) of TMD patients will experience symptom resolution either spontaneously or with nonsurgical treatment [51]. This resolution of symptoms occurs due to the underlying adaptive capacity of the TMJ. Given that internal derangement is a common MRI finding in $32-38 \%$ of asymptomatic patients and volunteers $[16,17]$ and that arthrocentesis or arthroscopy without disc repositioning is so successful, it is evident that the TMJ has the ability to adapt to the disc displacement in the vast majority of patients. Those patients with internal derangement and disc displacement that do not adapt are potential surgical candidates. It is the authors' preference to follow a surgical pyramid algorithm with most patients beginning with arthroscopy unless there are specific indications otherwise (e.g., ankylosis). Since no single surgical procedure carries a $100 \%$ success rate, patients who fail one level (phase 1) on the algorithm progress further up the pyramid to a second (phase 2) surgical procedure with phase 2 procedure being determined by the arthroscopic findings of phase 1.

\subsubsection{Arthrocentesis}

This minimally invasive procedure was introduced after the success of simple arthroscopy was recognized. Arthrocentesis in the TMJ was first described in 1987 by Murakami using a single needle pumping technique to create a hydraulic distention of the upper joint space [52]. Nitzan and Dolwick [18] subsequently modified the technique and used two needles. It provides lysis and lavage of the upper joint space

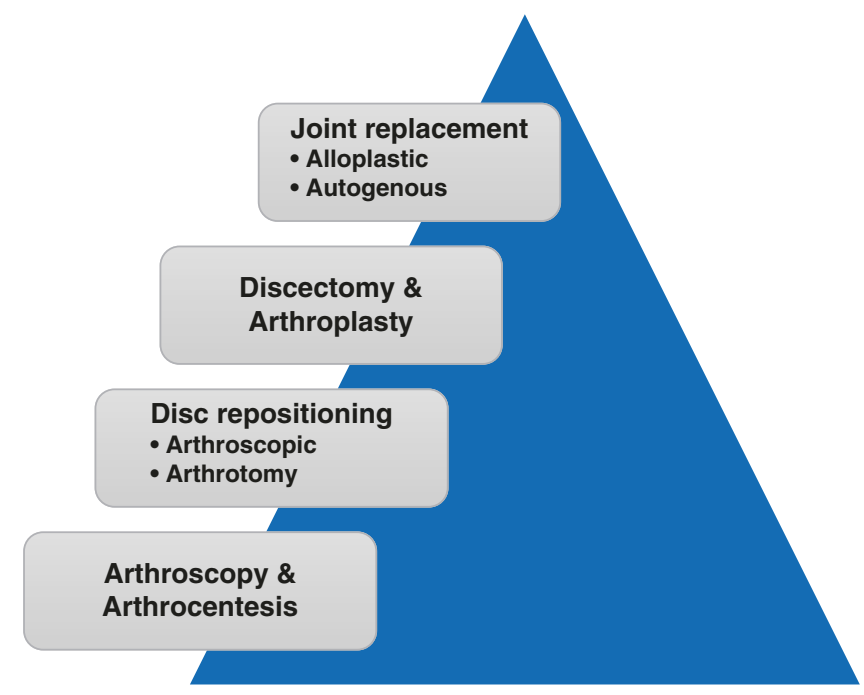

SURGICAL MANAGEMENT

(C)Association of Oral and Maxillofacial Surgeons of India

Fig.63.10 Surgical treatment options 


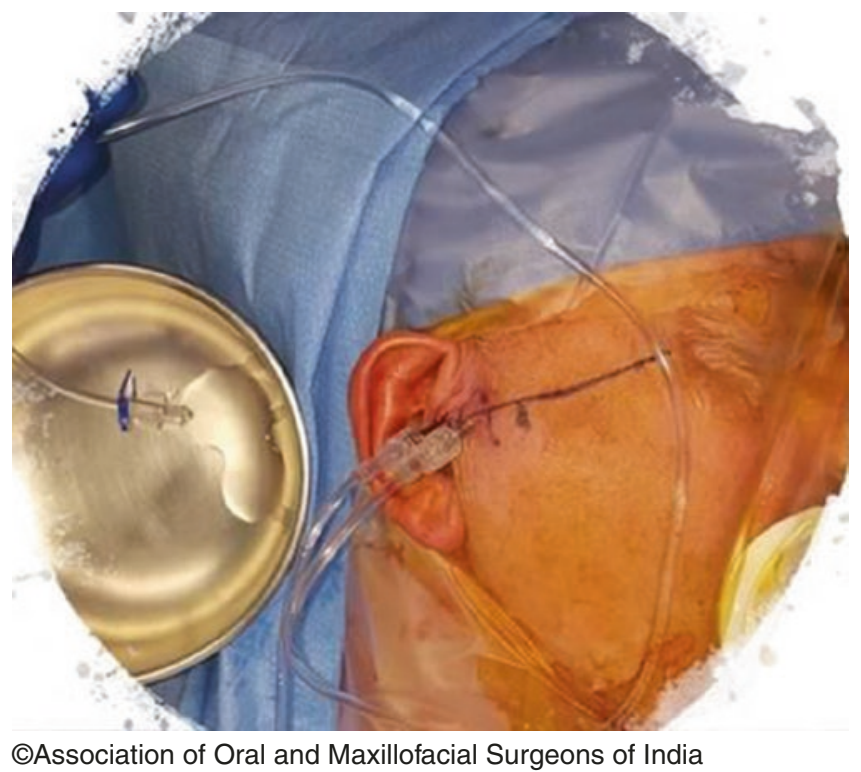

Fig. 63.11 Arthrocentesis-using the Holmlund-Hellsing markings measured along the trago-canthal line $(10 \mathrm{~mm}$ forward from mid-tragus and $2 \mathrm{~mm}$ down correspond to the glenoid fossa entry site)

using an inflow needle, an outflow needle, and at least $300 \mathrm{ml}$ Lactated Ringer's irrigation solution (Fig. 63.11). The lysis is accomplished by the hydraulic distention of the superior joint space, while the lavage removes inflammatory mediators, cytokines, and debris (Fig. 63.12). It is through the lysis and lavage that the adhesions are separated and the inflammatory mediators and debris are removed. Several authors have since reported success rates of arthrocentesis in the management of internal derangement ranging from 70 to 95\% [18-22].

\subsubsection{Arthroscopy}

Minimally invasive arthroscopic surgery for the TMJ was first performed by Ohnishi in 1974 and subsequently developed in the 1980s by several surgeons (Murakami, Holmlund, McCain, Saunders, and others). TMJ arthroscopy has proven to be an effective and reliable alternative to open joint surgery for many patients, resulting in reduced pain and improved maximum incisal opening [10-15] with success rates as high as $91 \%$ [12]. TMJ arthroscopy can be as simple as a visually assisted lysis and lavage or as complex as performing disc repositioning and fixation. The author uses McCain's terminology to categorize different levels of arthroscopy according to complexity and number of portals of entry (Table 63.5).

The authors preferred surgical sequence for performing a level 1 arthroscopy as outlined in Table 63.6 (Video 63.1). All arthroscopy should begin with an examination under anesthe-

\section{Arthrocentesis}

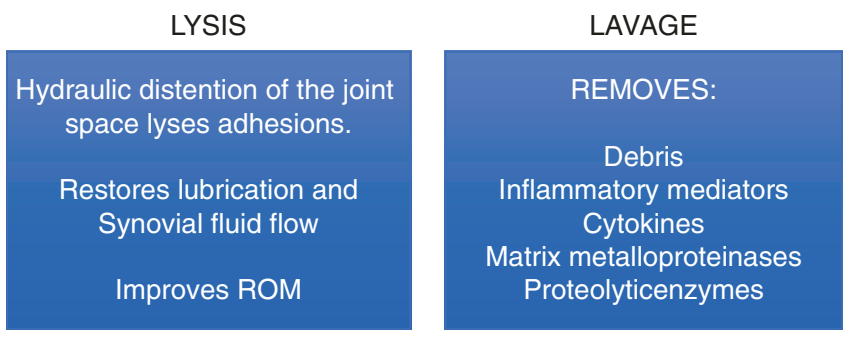

CAssociation of Oral and Maxillofacial Surgeons of India

Fig.63.12 Arthrocentesis—lysis and lavage

Table 63.5 Levels of TMJ arthroscopy (McCain's terminology)

Level I Arthroscopy

- Single puncture \& outflow needle

- Lysis\& lavage

- Diagnostic sweep

- Needle/scope adhesiolysis

Level II Arthroscopy

- Double puncture \& outflow needle

- Level I

- Instrumentation port (laser, coblation, grasper, probe etc.)

Level III Arthroscopy

- Triple puncture \& outflow needle

- Level II

- Discopexy(suture/screw)

Table 63.6 Level 1 arthroscopy sequence

- Examination under anesthesia

- Marking landmarks

- Superior joint space insufflation

- Trocar and cannula puncture

- Backwash

- Insert scope (confirm entry)

- Establish outflow

- Diagnostic sweep

- Medications (Steroid, hyaluronic acid or PRP etc.)

- Manipulation

sia of the TMJ. The EUA allows the surgeon to anticipate what might be encountered upon entering the joint arthroscopically. The range of condylar translation is noted, and whether translation is onto the peak of the articular eminence stops short of the peak or beyond the peak of the eminence as in subluxation and even dislocation. In addition, if there is very limited translation or just hinging, the surgeon might expect a tight joint space filled with adhesions and a fibrous arthrosis potentially making the arthroscopic puncture, joint access, and visualization difficult. Joint noises (clicking and crepitation) should be noted, and bone-on-bone crepitations are indicative of a perforation in the retrodiscal tissue. 
In addition to the lysis and lavage as in arthrocentesis (Table 63.6), a level 1 arthroscopy provides a diagnosis and identifies intra-articular pathology (Fig. 63.13a-f). A systematic diagnostic sweep through the entire superior joint space is performed to obtain the diagnostic information. Level 1 arthroscopy can be accomplished using a standard operative arthroscope (usually $1.9-2.7 \mathrm{~mm}$ ) or the more recently available disposable scopes $(1.2 \mathrm{~mm})$. While the image quality from a disposable scope is currently not as good as the traditional operative arthroscopes, it does allow for adequate visualization and a diagnosis.

Level 2 arthroscopy includes a second puncture with an operative cannula and allows for additional procedures such as disc mobilization, biopsy, laser ablation, or coblation to be performed. Video 63.2 shows the second cannula being inserted, disc mobilization with a probe, and laser ablation of hyperplastic polypoid synovitis.

Level 3 arthroscopy with multiple cannulas allows for more advanced techniques and disc repositioning with fixation, using sutures, wires, pins, or screws. The author uses a suture tech- nique to anchor the repositioned disc as shown in the Video 63.3. Figure 63.14a, b shows the suture placed through the posterior band of the disc anchoring it into the reduced position. The arthroscopic suture video clearly shows how tightening the suture reduces the anteriorly displaced disc.

Several surgeons have described and published techniques to reposition and fixate the displaced disc [53-59]. Success in the early reports of arthroscopic disc repositioning was not high. Yang reported better success rates with partial and later complete anterior release of the disc from its anterior attachment and suggested that relapse rates without complete anterior release are high [55]. While more recent success rates of disc repositioning as high as 95.3\% [60] have been reported, many of these studies have relatively short-term follow-up and/or no MRI confirmation of longterm stability of the disc repositioning.

It is the authors' opinion that level 3 arthroscopy should be performed primarily for functional reasons, e.g., a mechanically obstructive click, closed lock, or subluxation. In McCain's publication on arthroscopic discopexy [59], the
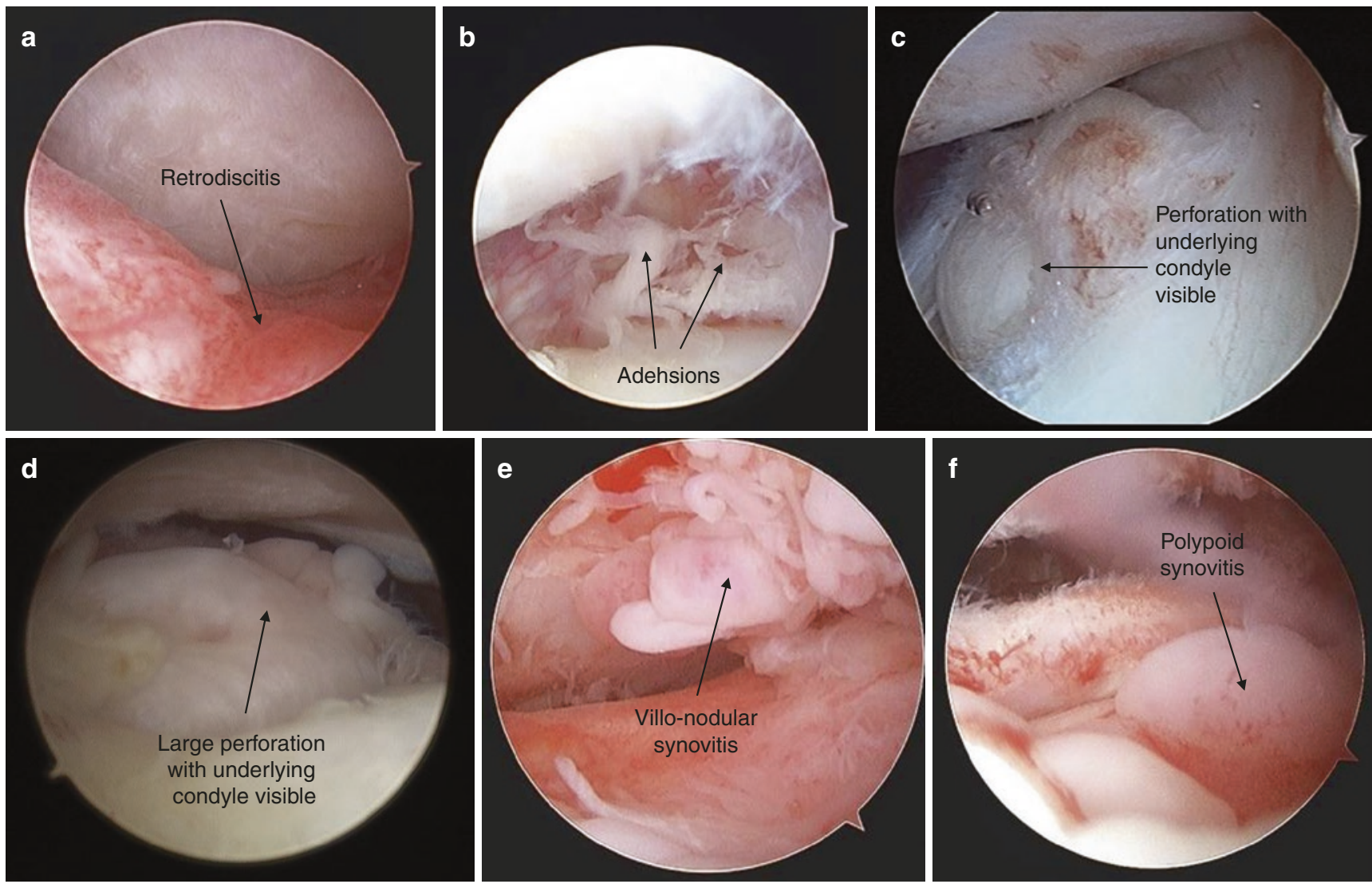

(C)Association of Oral and Maxillofacial Surgeons of India

Fig.63.13 (a-f) Arthroscopic pathology. (a) Retrodiscitis (b) Adhesions (c) Small disc tear/perforation (d) Large perforation with condyle visible (e) Villonodular synovitis (f) Polypoid synovitis 
Fig. $63.14(a, b)$

Arthroscopic suture discopexy-suture placed through the posterior band of the disc anchoring it into the correct reduced position
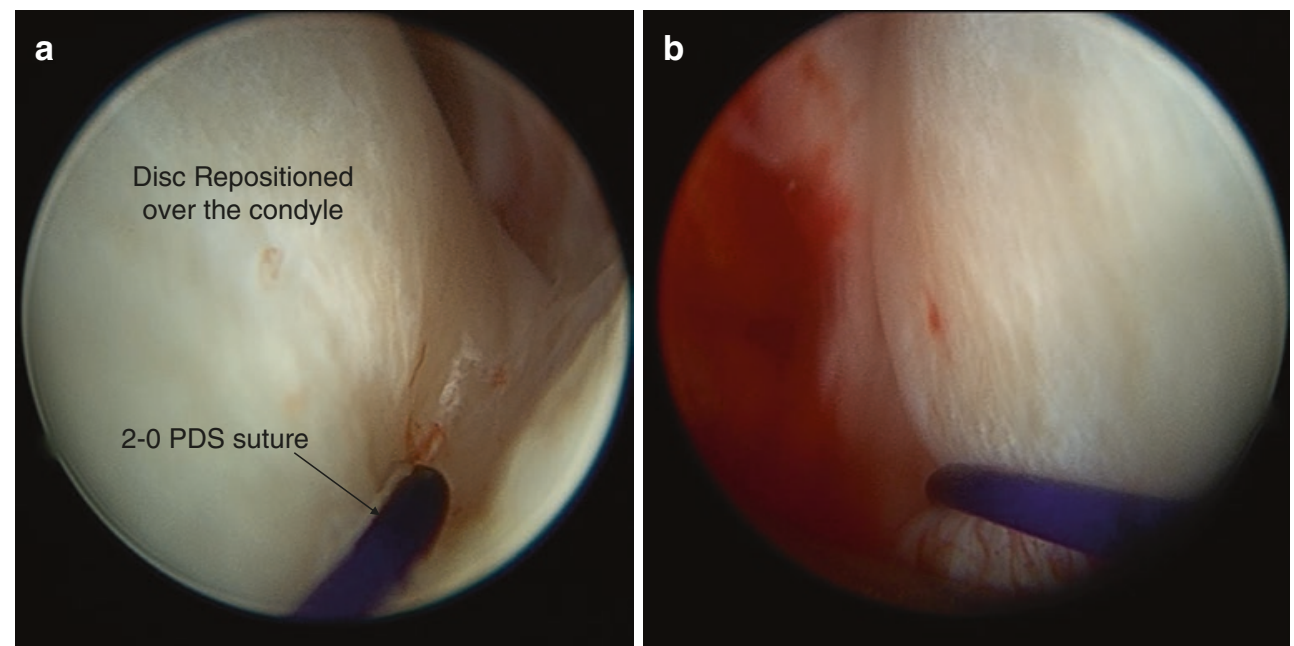

CAssociation of Oral and Maxillofacial Surgeons of India success rate in 42 joints was $86.7 \%$ in Wilkes II and III but only $25 \%$ in Wilkes IV and V which emphasizes that case selection is a key element to success. For disc repositioning to be indicated and have good outcomes, the disc must be salvageable, and there must be sufficient posterior joint space height in which to reposition the disc. In other words, the disc must be intact, and MRI evaluation must confirm normal disc morphology with adequate posterior joint space height in which to reposition the disc. If the joint space has collapsed as is often the case in longer-standing/chronic disc displacement, the load placed during function on the repositioned disc will be excessive, and the fixation will likely fail, leading to displacement again. Postoperatively, all patients will notice a malocclusion with slight mandibular deviation to the contralateral side. However, the majority of these malocclusions will resolve within 3 weeks. Additional factors to success are the postoperative physical therapy and dietary instructions. The author instructs his patients to perform "limited range of motion" exercises for the first 3 weeks to minimize the risk of the fixation failing or tearing through the disc. This is achieved by instructing the patient to keep the tongue on the roof of the mouth while performing opening exercises. The diet should be soft with minimal chewing and as for all surgical cases and any parafunctional habits should be well controlled. After 3 weeks, the patients gradually increase their mouth opening with daily stretching exercises. Associated myalgias may improve once the joint pain and function improve following arthroscopy, but often concomitant nonsurgical treatment of the muscle disorder is also required.

At the end of the arthroscopic procedure, the surgeon has the option of injecting medications including steroid, hyaluronic acid (HA), and platelet-rich plasma (PRP).

\subsubsection{Viscosupplementation with Hyaluronic Acid}

Hyaluronic acid is a glycosaminoglycan polysaccharide naturally found in synovial fluid. It is produced by the chondrocytes and synoviocytes and plays an important role in joint function and nutrition. HA is the main contributor to the viscosity of synovial fluid and provides protection under joint loading. Inflammatory disorders of the TMJ including internal derangement are associated with reduced quantity and quality of HA through a process of destruction and also the production of HA that is lower in molecular weight $[61,62]$. The short half-life of injected HA makes it unlikely that its effectiveness is due to restoration of the viscosity of the synovial fluid [63]. It is suggested that supplementation with injectable HA could have anti-inflammatory and analgesic effects [64]. Altman suggested that injection of HA could lead to repair of the articular cartilage/fibrocartilage and normalize the synthesis of endogenous HA [65].

Viscosupplementation has been described in orthopedic literature for many years, but there are discrepancies in the evidence to support the widespread use of intra-articular hyaluronic acid to treat knee osteoarthritis. However, several recent studies have shown hyaluronic acid to be a viable treatment option showing longer-term improvement in both knee pain and function. Unfortunately, similar uncertainty exists regarding the effectiveness of viscosupplementation using hyaluronic acid in the TMJ [66-68]. Beyond viscosupplementation, there are some additional benefits to using HA in TMJ arthroscopy. If the surgeon is having difficulty maneuvering the scope because of a tight joint space, the lubricant properties of HA may be helpful in minimizing iatrogenic damage to the joint surfaces and disc. It is also help- 
ful at the end of the procedure in reducing the bleeding from a hyperemic joint.

\subsubsection{Platelet-Rich Plasma}

Is a concentration of platelets and growth factors taken from autologous blood. It has reported beneficial effects in joint degeneration and tendinopathy [69-72], and there is both literature supporting its effectiveness in TMJ arthroscopy [73-75] and conflicting literature reporting no benefit [76, 77]. Therefore, the use of PRP after TMJ arthroscopy remains controversial, and further studies are needed [78].

\subsubsection{Open Joint Surgery and Arthroplasty}

The effectiveness of minimally invasive procedures such as arthrocentesis and arthroscopy has significantly reduced the frequency and volume of open joint surgery (disc repositioning or discectomy). However, currently there are very few surgeons trained in the advanced technique of arthroscopic discopexy, and so for patients who fail level 1 or 2 arthroscopy and require disc repositioning surgery, open joint surgery with disc repositioning may be the next surgical step in moving up the surgical pyramid. Annandale first published "On displacement of the inter-articular cartilage of the lower jaw and its treatment by operation" in 1887 [3], but it wasn't until later that surgery for internal derangement became popular. Surgical interest in disc displacement began with reports from McCarty and Farrar [5] claiming disc repositioning success rates of $94 \%$ using a wedge resection and suture plication technique. However, other surgeons were not as successful, and the long-term stability of suture plication techniques was low, leading to multiple variations of open surgical disc repositioning and methods of fixation [79-82]. In 2001, Wolford reported a more rigid fixation technique using a Mitek mini-bone anchor to fixate the repositioned disc [83]. In this technique, the anterior and lateral disc attachments are released allowing passive disc repositioning. The disc is separated at its junction with the retrodiscal tissue, and Mitek anchor is inserted into a 2-mm hole drilled into the posterior condyle $8-10 \mathrm{~mm}$ below articulating surface. Two 0-Ethibond braided sutures are inserted through the posterior band of the disc in a mattress suture fashion fixing the disc to the Mitek anchor (Fig. 63.15a-c). Although radiographs at the longest follow-up showed no condylar resorption and stable position of the metal anchor, the stability of the disc repositioning was not evaluated by MRI. Despite this, Wolford reported that there was a statistically significant reduction in TMJ pain, facial pain, headaches, TMJ noises, and disability and improvement in jaw function and diet.
Alternative fixation and anchoring devices are available on the market today. He et al. use a self-drilling miniscrew and have modified the technique to include a complete anterior release and overcorrection of the disc position for better stability of the repositioning. They report stable short-term (mean 10 months) disc position on MRI in $98.6 \%$ of patients [84]. Zhou et al. evaluated the same technique in 149 joints and the long-term stability of the repositioned disc on MRI at a mean longest follow-up of 23.4 months (range 12-84 months) and reported that $95.3 \%$ of discs were still in position, whereas $4.7 \%$ had relapsed anteriorly [85]. They also reported new condylar bone formation in $74.5 \%$ of joints and even greater in young patients (under the age of 20), $90 \%$ of whom had new bone formation, suggesting that adolescents may have growth ability after disc repositioning which might reduce facial asymmetry. Mandibular asymmetry in unilateral disc displacement has been reported in the literature. Xie et al. [86] reported mandibular asymmetry in $72 \%$ of 165 patients with anterior disc displacement and the severity of the asymmetry correlated with the degree of disc displacement, disc deformity, and condylar shortening. Therefore, disc repositioning may allow for condylar bone formation and reduce mandibular asymmetry that may develop as a result of the displaced disc. The overall clinical outcomes of disc repositioning surgery are good with reduced pain, improved diet, and improved range of motion with $94 \%$ of patients reporting improved quality of life [87].

For those patients with discs that are not salvageable, discectomy is the next step in the surgical pyramid. This involves removal of the disc and the area surrounding any perforation in the retrodiscal tissue, and possible replacement of the disc is an option. There are several long-term studies demonstrating greater than $80 \%$ success rates following discectomy [88-91] with a few following patients for more than 20 years [92-94] with almost complete resolution of pain and restoration of normal diet. A 5-year follow-up study of discectomy without any disc replacement reported $87 \%$ of patients fulfilling the criteria for success with reduced pain on function and increased mouth opening, although pain at rest was unchanged [95]. Following discectomy, radiographs will show altered condylar morphology in the operated joint, and this is thought to be an adaptive process of remodeling because the reduced symptoms do not correlate with the radiographic changes [96, 97]. While the literature demonstrates the long-term success of discectomy without replacement $[89,90]$, disc replacement options have been explored in attempts to reduce the crepitation these patients experience and also with the intent to reduce the 
Fig. 63.15 (a-c) Use of a Mitek anchor according to Wolford's technique
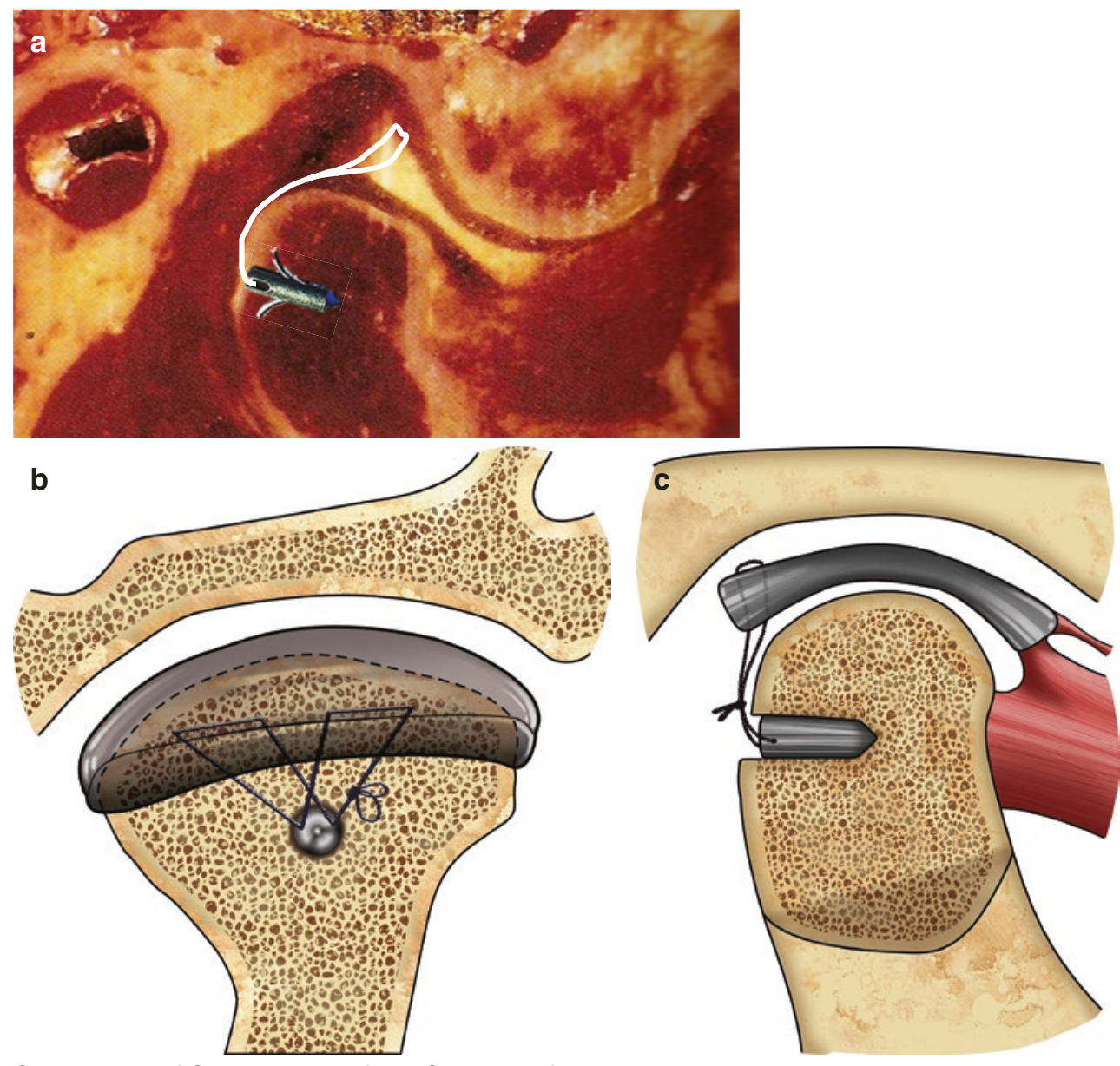

CAssociation of Oral and Maxillofacial Surgeons of India remodeling. Many autogenous, allogeneic, and alloplastic disc replacements have been tried with varying degrees of success (Table 63.7), and some such as Proplast have caused joint destruction necessitating joint reconstruction and replacement [99]. At the current time, there is a lack of evidence to support the routine use of any disc replacement after discectomy.

The use of tissue engineering is emerging as a promising option to repair or potentially replace the diseased tissues of the TMJ and may provide additional treatment options in the future. Progress has already been made toward the development of appropriate tools for TMJ tissue engineering. The goal is to develop an approach to produce new tissues de novo (neotissues) with qualities similar to the native TMJ. This may be accomplished by (1) in situ tissue engineering, which involves an acellular scaffold matrix attracting local cells (cell homing) guiding the process of regeneration, and (2) ex vivo cell seeding on
Table 63.7 Disc replacement options [98]

\begin{tabular}{|l|l} 
Alloplastic & $\begin{array}{l}\text { Methyl methacrylate } \\
\text { Silastic } \\
\text { Proplast-Teflon } \\
\text { Fossa prosthesis }\end{array}$ \\
\hline Allogenic & $\begin{array}{l}\text { Dura (cryopreserved) } \\
\text { Cartilage (lyophilized, freeze-dried) } \\
\text { Temporalis muscle/fascia } \\
\text { Eur/rib cartilage }\end{array}$ \\
& $\begin{array}{l}\text { Dermis skin grafts } \\
\text { Abdominal fat }\end{array}$ \\
Bovine collagen/cartilage
\end{tabular}

the scaffold, which provides enough competent cells to orchestrate the regenerative process. The second strategy appears better suited for TMJ regeneration because of its limited capacities of self-repair and the rapid regeneration expected [100]. 
Table 63.9 Algorithm and decision framework
LEVEL $1 / 2$

ARTHROSCOPY

(Lysis, lavage, debridement, biopsy \& disc mobilization)

there are functional problems (mechanically obstructive click, closed lock or subluxation) Is the disc salvageable with normal morphology? AND is the posterior joint space sufficient for disc repositioning?

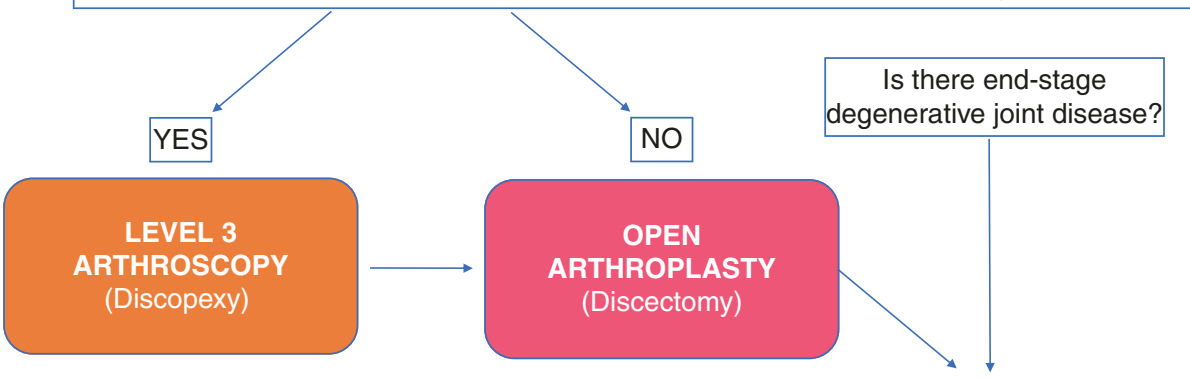

TOTAL JOINT

RECONSTRUCTION/REPLACEMNT
Table 63.8 Failed level 1 or 2 arthroscopy—now what?

-Wilkes II/III/early IV $\rightarrow$ Discopexy

- Wilkes IV/V $\rightarrow$ Advanced debridement

- Primary arthritis $\rightarrow$ Establish diagnosis

- Rheumatology referral

- Joint replacement

\subsection{Conclusion}

Internal derangement of the TMJ is a common problem resulting in pain and limited function for some patients. While the vast majority of patients adapt to the internal derangement over time or with nonsurgical treatment, surgery may be indicated for those with ongoing problems. There are no surgical procedures for the TMJ that have a $100 \%$ success rate; it therefore makes sense to undertake the least invasive procedures first. The surgical pyramid presented in this chapter provides a stepwise progression for TMJ surgical patients. In the authors' clinical practice, most surgical patients begin with a level 1 or 2 arthroscopic surgery and only step up the pyramid if this fails. If the diagnosis after arthroscopy is Wilkes II, III, or early IV, phase 2 procedure would be disc repositioning and discopexy if the disc is intact and has normal morphology and there is sufficient posterior joint space in which to reposition it. In Wilkes IV and V, phase 2 procedure would be joint debridement and discectomy (Table 63.8).
Finally, Table 63.9 presents an algorithm and decision framework that guides the progression through the various surgical procedures discussed in this chapter.

\section{References}

1. Steele AB. Internal derangement of the knee joint. BMJ. 1855;3(114):224-5.

2. Annandale T. An address on internal derangements of the knee-joint and their treatment by operation. $\mathrm{Br}$ Med $\mathrm{J}$. 1887;1(1363):319-21.

3. Annandale T. On displacement of the inter-articular cartilage of the lower jaw, and its treatment by operation. Lancet. 1887;129(3313):411.

4. Porter RS. In: Porter RS, editor. The Merck manual of diagnosis and therapy, 20th ed. 2018.

5. McCarty WL, Farrar WB. Surgery for internal derangements of the temporomandibular joint. J Prosthet Dent. 1979;42(2):191-6.

6. Kaplan PA, Ruskin JD, Tu HK, Knibbe MA. Erosive arthritis of the temporomandibular joint caused by Teflon-Proplast implants: plain film features. AJR Am J Roentgenol. 1988;151(2):337-9.

7. Smith RM, Goldwasser MS, Sabol SR. Erosion of a TeflonProplast implant into the middle cranial fossa. J Oral Maxillofac Surg. 1993;51(11):1268-71.

8. Lypka M, Yamashita D-DR. Exuberant foreign body giant cell reaction to a teflon/proplast temporomandibular joint implant: report of a case. J Oral Maxillofac Surg. 2007;65(9):1680-4.

9. Wilkes $\mathrm{CH}$. Internal derangements of the temporomandibular joint. Pathologic variations. Arch Otolaryngol Head Neck Surg. 1989;115:469-477.

10. Sanders B, Buoncristiani R. Diagnostic and surgical arthroscopy of the temporomandibular joint: clinical experience with 137 procedures over a 2-year period. J Craniomandib Disord. 1987;1(3):202-13. 
11. Moses JJ, Poker ID. TMJ arthroscopic surgery: an analysis of 237 patients. J Oral Maxillofac Surg. 1989;47(8):790-4.

12. McCain JP, Sanders B, Koslin MG, Quinn JH, Peters PB, Indresano AT, et al. Temporomandibular joint arthroscopy: a 6-year multicenter retrospective study of 4,831 joints. J Oral Maxillofac Surg. 1992;50(9):926-30.

13. Hoffman DC, Cubillos L. The effect of arthroscopic surgery on mandibular range of motion. Cranio. 1994;12(1):11-8.

14. Dimitroulis G. A review of 56 cases of chronic closed lock treated with temporomandibular joint arthroscopy. J Oral Maxillofac Surg. 2002;60(5):519-24.

15. Dimitroulis G. Outcomes of temporomandibular joint arthroscopy in patients with painful but otherwise normal joints. J Craniomaxillofac Surg. 2015;43(6):940-3.

16. Kircos LT, Ortendahl DA, Mark AS, Arakawa M. Magnetic resonance imaging of the TMJ disc in asymptomatic volunteers. J Oral Maxillofac Surg. 1987;45(10):852-4.

17. Katzberg RW, Westesson PL, Tallents RH, Drake CM. Anatomic disorders of the temporomandibular joint disc in asymptomatic subjects. J Oral Maxillofac Surg. 1996;54(2):147-53.

18. Nitzan DW, Dolwick MF, Martinez GA. Temporomandibular joint arthrocentesis: a simplified treatment for severe, limited mouth opening. J Oral Maxillofac Surg. 1991;49(11):1163-7.

19. Nitzan DW, Samson B, Better H. Long-term outcome of arthrocentesis for sudden-onset, persistent, severe closed lock of the temporomandibular joint. J Oral Maxillofac Surg. 1997;55(2):151-7.

20. Dimitroulis G, Dolwick MF, Martinez A. Temporomandibular joint arthrocentesis and lavage for the treatment of closed lock: a follow-up study. Br J Oral Maxillofac Surg. 1995;33(1): 23-6.

21. Hosaka H, Murakami K, Goto K, Iizuka T. Outcome of arthrocentesis for temporomandibular joint with closed lock at 3 years follow-up. Oral Surg Oral Med Oral Pathol Oral Radiol Endod. 1996;82(5):501-4.

22. Sembronio S, Albiero AM, Toro C, Robiony M, Politi M. Is there a role for arthrocentesis in recapturing the displaced disc in patients with closed lock of the temporomandibular joint? Oral Surg Oral Med Oral Pathol Oral Radiol Endod. 2008;105(3):274-80.

23. Quinn JH, Bazan NG. Identification of prostaglandin E2 and leukotriene B4 in the synovial fluid of painful, dysfunctional temporomandibular joints. J Oral Maxillofac Surg. 1990;48(9):968-71.

24. Shafer DM, Assael L, White LB, Rossomando EF. Tumor necrosis factor-alpha as a biochemical marker of pain and outcome in temporomandibular joints with internal derangements. J Oral Maxillofac Surg. 1994;52(8):786-91.

25. Kopp S. Neuroendocrine, immune, and local responses related to temporomandibular disorders. J Orofac Pain. 2001;15(1):9-28.

26. Kubota E, Kubota T, Matsumoto J, Shibata T, Murakami KI. Synovial fluid cytokines and proteinases as markers of temporomandibular joint disease. J Oral Maxillofac Surg. 1998;56(2):192-8.

27. Schiffman E, Ohrbach R, Truelove E, Look J, Anderson G, Goulet J-P, et al. Diagnostic Criteria for Temporomandibular Disorders (DC/TMD) for Clinical and Research Applications: recommendations of the International RDC/TMD Consortium Network and Orofacial Pain Special Interest Group $\dagger$. J Oral Facial Pain Headache. 2014;28(1):6-27.

28. Farrar WB. Letter: myofascial pain dysfunction syndrome. J Am Dent Assoc. 1975;91(2):205-6.

29. Agerberg G, Inkapööl I. Craniomandibular disorders in an urban Swedish population. J Craniomandib Disord. 1990;4(3):154-64.

30. Santos KCP, Dutra MEP, Warmling LV, Oliveira JX. Correlation among the changes observed in temporomandibular joint internal derangements assessed by magnetic resonance in symptomatic patients. J Oral Maxillofac Surg. 2013;71(9):1504-12.
31. Rinchuse DJ, McMinn JT. Summary of evidence-based systematic reviews of temporomandibular disorders. Am J Orthod Dentofacial Orthop. 2006;130(6):715-20.

32. Türp JC, Schindler H. The dental occlusion as a suspected cause for TMDs: epidemiological and etiological considerations. J Oral Rehabil. 2012;39(7):502-12.

33. Okeson JP. Management of temporomandibular disorders and occlusion. St. Louis: Elsevier Health Sciences; 2007. 1 p.

34. Honda K, Larheim TA, Sano T, Hashimoto K, Shinoda K, Westesson PL. Thickening of the glenoid fossa in osteoarthritis of the temporomandibular joint. An autopsy study. Dentomaxillofac Radiol. 2001 Jan;30(1):10-3.

35. Larheim TA. Current trends in temporomandibular joint imaging. Oral Surg Oral Med Oral Pathol Oral Radiol Endod. 1995;80(5):555-76.

36. Song YW, Kang EH. Autoantibodies in rheumatoid arthritis: rheumatoid factors and anticitrullinated protein antibodies. QJM. 2010;103(3):139-46.

37. Niewold TB, Harrison MJ, Paget SA. Anti-CCP antibody testing as a diagnostic and prognostic tool in rheumatoid arthritis. QJM. 2007;100(4):193-201.

38. García-Kutzbach A, Chacón-Súchite J, García-Ferrer H, Iraheta I. Reactive arthritis: update 2018. Clin Rheumatol. 2018;37(4):869-74.

39. Sato S, Goto S, Nasu F, Motegi K. Natural course of disc displacement with reduction of the temporomandibular joint: changes in clinical signs and symptoms. J Oral Maxillofac Surg. 2003;61(1):32-4.

40. Sato S, Kawamura H, Nagasaka H, Motegi K. The natural course of anterior disc displacement without reduction in the temporomandibular joint: follow-up at 6, 12, and 18 months. J Oral Maxillofac Surg. 1997;55(3):234-8.

41. Kurita K, Westesson PL, Yuasa H, Toyama M, Machida J, Ogi N. Natural course of untreated symptomatic temporomandibular joint disc displacement without reduction. J Dent Res. 1998;77(2):361-5.

42. Costen JB. A syndrome of ear and sinus symptoms dependent upon disturbed function of the temporomandibular joint. 1934. Annal Otol Rhinol Laryngol. 1997;106(10 Pt 1):805-19.

43. Block LS. Diagnosis and treatment of disturbances of the temporomandibular joint especially in relation to vertical dimension. J Am Dent Assoc. 1947;34(4):253-60.

44. Posselt U. The temporomandibular joint syndrome and occlusion. J Prosthet Dent. 1971;25(4):432-8.

45. Lundh H, Westesson PL, Eriksson L, Brooks SL. Temporomandibular joint disk displacement without reduction. Treatment with flat occlusal splint versus no treatment. Oral Surg Oral Med Oral Pathol. 1992;73(6):655-8.

46. Truelove E, Huggins KH, Mancl L, Dworkin SF. The efficacy of traditional, low-cost and nonsplint therapies for temporomandibular disorder: a randomized controlled trial. J Am Dent Assoc. 2006;137(8):1099-107.

47. Greene CS, Goddard G, Macaluso GM, Mauro G. Topical review: placebo responses and therapeutic responses. How are they related? J Orofac Pain. 2009;23(2):93-107.

48. Greene CS, Laskin DM. Splint therapy for the myofascial paindysfunction (MPD) syndrome: a comparative study. J Am Dent Assoc. 1972;84(3):624-8.

49. Minakuchi H, Kuboki T, Matsuka Y, Maekawa K, Yatani H, Yamashita A. Randomized controlled evaluation of non-surgical treatments for temporomandibular joint anterior disk displacement without reduction. J Dent Res. 2001;80(3):924-8.

50. Klasser GD, Greene CS. Oral appliances in the management of temporomandibular disorders. Oral Surg Oral Med Oral Pathol Oral Radiol Endod. 2009;107(2):212-3. 
51. Randolph CS, Greene CS, Moretti R, Forbes D, Perry HT. Conservative management of temporomandibular disorders: a posttreatment comparison between patients from a university clinic and from private practice. Am J Orthod Dentofacial Orthop. 1990;98(1):77-82.

52. Murakami KI, lizuka T, Matsuki M, Ono T. Recapturing the persistent anteriorly displaced disk by mandibular manipulation after pumping and hydraulic pressure to the upper joint cavity of the temporomandibular joint. Cranio. 1987;5(1):17-24.

53. McCain JP, Podrasky AE, Zabiegalski NA. Arthroscopic disc repositioning and suturing: a preliminary report. J Oral Maxillofac Surg. 1992;50(6):568-79.

54. Zhang S-Y, Liu X-M, Yang C, Cai X-Y, Chen M-J, Haddad MS, et al. New arthroscopic disc repositioning and suturing technique for treating internal derangement of the temporomandibular joint: part II-magnetic resonance imaging evaluation. J Oral Maxillofac Surg. 2010;68(8):1813-7.

55. Yang C, Cai X-Y, Chen M-J, Zhang S-Y. New arthroscopic disc repositioning and suturing technique for treating an anteriorly displaced disc of the temporomandibular joint: part I-technique introduction. Int J Oral Maxillofac Surg. 2012;41(9):1058-63.

56. Zhu Y, Zheng C, Deng Y, Wang Y. Arthroscopic surgery for treatment of anterior displacement of the disc without reduction of the temporomandibular joint. Br J Oral Maxillofac Surg. 2012;50(2):144-8.

57. Goizueta-Adame CC, Pastor-Zuazaga D, Orts Bañón JE. Arthroscopic disc fixation to the condylar head. Use of resorbable pins for internal derangement of the temporomandibular joint (stage II-IV). Preliminary report of 34 joints. J Craniomaxillofac Surg. 2014;42(4):340-6.

58. Goizueta-Adame CC, Muñoz-Guerra MF. The posterior double pass suture in repositioning of the temporomandibular disc during arthroscopic surgery: a report of 16 cases. J Craniomaxillofac Surg. 2012;40(1):86-91.

59. McCain JP, Hossameldin RH, Srouji S, Maher A. Arthroscopic discopexy is effective in managing temporomandibular joint internal derangement in patients with Wilkes stage II and III. J Oral Maxillofac Surg. 2015;73(3):391-401.

60. Liu X, Zheng J, Cai X, Abdelrehem A, Yang C. Techniques of Yang's arthroscopic discopexy for temporomandibular joint rotational anterior disc displacement. Int J Oral Maxillofac Surg. 2018;48(6):769-78.

61. Nitzan DW. The process of lubrication impairment and its involvement in temporomandibular joint disc displacement: a theoretical concept. J Oral Maxillofac Surg. 2001;59(1):36-45.

62. Sharma A, Rana AS, Jain G, Kalra P, Gupta D, Sharma S. Evaluation of efficacy of arthrocentesis (with normal saline) with or without sodium hyaluronate in treatment of internal derangement of $\mathrm{TMJ}-\mathrm{a}$ prospective randomized study in 20 patients. J Oral Biol Craniofac Res. 2013;3(3):112-9.

63. Machado RC, Capela S, Rocha FAC. Polysaccharides as viscosupplementation agents: structural molecular characteristics but not rheology appear crucial to the therapeutic response. Front Med (Lausanne). 2017;4:82

64. Gencer ZK, Özkiriş M, Okur A, Korkmaz M, Saydam L. A comparative study on the impact of intra-articular injections of hyaluronic acid, tenoxicam and betametazon on the relief of temporomandibular joint disorder complaints. J Craniomaxillofac Surg. 2014;42(7):1117-21.

65. Altman RD, Manjoo A, Fierlinger A, Niazi F, Nicholls M. The mechanism of action for hyaluronic acid treatment in the osteoarthritic knee: a systematic review. BMC Musculoskelet Disord. 2015;16(1):321.

66. Ferreira N, Masterson D, Lopes de Lima R, de Souza Moura B, Oliveira AT, Kelly da Silva Fidalgo T, et al. Efficacy of viscosupplementation with hyaluronic acid in temporomandibu- lar disorders: a systematic review. J Craniomaxillofac Surg. 2018;46(11):1943-52.

67. Bouloux GF, Chou J, Krishnan D, Aghaloo T, Kahenasa N, Smith JA, et al. Is hyaluronic acid or corticosteroid superior to lactated ringer solution in the short-term reduction of temporomandibular joint pain after arthrocentesis? Part 1. J Oral Maxillofac Surg. 2017;75(1):52-62.

68. Bouloux GF, Chou J, Krishnan D, Aghaloo T, Kahenasa N, Smith $\mathrm{JA}$, et al. Is hyaluronic acid or corticosteroid superior to lactated ringer solution in the short term for improving function and quality of life after arthrocentesis? Part 2. J Oral Maxillofac Surg. 2017;75(1):63-72.

69. Foster TE, Puskas BL, Mandelbaum BR, Gerhardt MB, Rodeo SA. Platelet-rich plasma: from basic science to clinical applications. Am J Sports Med. 2009;37(11):2259-72.

70. Dai W-L, Zhou A-G, Zhang H, Zhang J. Efficacy of platelet-rich plasma in the treatment of knee osteoarthritis: a meta-analysis of randomized controlled trials. Arthroscopy. 2017;33(3):659-670. e1.

71. Fitzpatrick J, Bulsara MK, O'Donnell J, McCrory PR, Zheng $\mathrm{MH}$. The effectiveness of platelet-rich plasma injections in gluteal tendinopathy: a randomized, double-blind controlled trial comparing a single platelet-rich plasma injection with a single corticosteroid injection. Am J Sports Med. 2018;46(4):933-9.

72. Fitzpatrick J, Bulsara M, Zheng MH. The effectiveness of plateletrich plasma in the treatment of tendinopathy: a meta-analysis of randomized controlled clinical trials. Am J Sports Med. 2017;45(1):226-33.

73. Bousnaki M, Bakopoulou A, Koidis P. Platelet-rich plasma for the therapeutic management of temporomandibular joint disorders: a systematic review. Int J Oral Maxillofac Surg. 2018;47(2):188-98.

74. Hegab AF, Ali HE, Elmasry M, Khallaf MG. Platelet-rich plasma injection as an effective treatment for temporomandibular joint osteoarthritis. J Oral Maxillofac Surg. 2015;73(9):1706-13.

75. Chung P-Y, Lin M-T, Chang H-P. Effectiveness of platelet-rich plasma injection in patients with temporomandibular joint osteoarthritis: a systematic review and meta-analysis of randomized controlled trials. Oral Surg Oral Med Oral Pathol Oral Radiol. 2019;127(2):106-16.

76. Cömert Kiliç S, Güngörmüş M. Is arthrocentesis plus plateletrich plasma superior to arthrocentesis plus hyaluronic acid for the treatment of temporomandibular joint osteoarthritis: a randomized clinical trial. Int J Oral Maxillofac Surg. 2016;45(12):1538-44.

77. Fernández Sanromán J, Fernández Ferro M, Costas López A, Arenaz Bua J, López A. Does injection of plasma rich in growth factors after temporomandibular joint arthroscopy improve outcomes in patients with Wilkes stage IV internal derangement? A randomized prospective clinical study. Int J Oral Maxillofac Surg. 2016;45(7):828-35.

78. Haigler MC, Abdulrehman E, Siddappa S, Kishore R, Padilla M, Enciso R. Use of platelet-rich plasma, platelet-rich growth factor with arthrocentesis or arthroscopy to treat temporomandibular joint osteoarthritis: Systematic review with meta-analyses. J Am Dent Assoc. 2018;149(11):940-2.

79. Leopard PJ. Anterior dislocation of the temporomandibular disc. Br J Oral Maxillofac Surg. 1984;22(1):9-17.

80. Walker RV, Kalamchi S. A surgical technique for management of internal derangement of the temporomandibular joint. J Oral Maxillofac Surg. 1987;45(4):299-305.

81. Weinberg S, Cousens G. Meniscocondylar plication: a modified operation for surgical repositioning of the ectopic temporomandibular joint meniscus. Rationale and operative technique. Oral Surg Oral Med Oral Pathol. 1987;63(4):393-402.

82. Zetz MR, Ash DC. Double-layer closure for temporomandibular joint discoplasty. J Oral Maxillofac Surg. 1990;48(4):427-9. 
83. Mehra P, Wolford LM. The Mitek mini anchor for TMJ disc repositioning: surgical technique and results. Int J Oral Maxillofac Surg. 2001;30(6):497-503.

84. He D, Yang C, Zhang S, Wilson JJ. Modified temporomandibular joint disc repositioning with miniscrew anchor: part I-surgical technique. J Oral Maxillofac Surg. 2015;73(1):47.e1-9.

85. Zhou Q, Zhu H, He D, Yang C, Song X, Ellis E. Modified temporomandibular joint disc repositioning with mini-screw anchor: part ii-stability evaluation by magnetic resonance imaging. J Oral Maxillofac Surg. 2019;77(2):273-9.

86. Xie Q, Yang C, He D, Cai X, Ma Z. Is mandibular asymmetry more frequent and severe with unilateral disc displacement? J Craniomaxillofac Surg. 2015;43(1):81-6.

87. Abramowicz S, Dolwick MF. 20-year follow-up study of disc repositioning surgery for temporomandibular joint internal derangement. J Oral Maxillofac Surg. 2010;68(2):239-42.

88. Merrill RG. Historical perspectives and comparisons of TMJ surgery for internal disk derangements and arthropathy. Cranio. 1986;4(1):74-85.

89. McKenna SJ. Discectomy for the treatment of internal derangements of the temporomandibular joint. J Oral Maxillofac Surg. 2001;59(9):1051-6.

90. Holmlund AB, Gynther G, Axelsson S. Discectomy in treatment of internal derangement of the temporomandibular joint. Follow-up at 1, 3, and 5 years. Oral Surg Oral Med Oral Pathol. 1993;76(3):266-71.

91. Miloro M, McKnight M, Han MD, Markiewicz MR. Discectomy without replacement improves function in patients with internal derangement of the temporomandibular joint. J Craniomaxillofac Surg. 2017;45(9):1425-31.
92. Silver CM. Long-term results of meniscectomy of the temporomandibular joint. Cranio. 1984;3(1):46-57.

93. Takaku S, Toyoda T. Long-term evaluation of discectomy of the temporomandibular joint. J Oral Maxillofac Surg. 1994;52(7):722-6.

94. Tolvanen M, Oikarinen VJ, Wolf J. A 30-year follow-up study of temporomandibular joint meniscectomies: a report on five patients. Br J Oral Maxillofac Surg. 1988;26(4):311-6.

95. Nyberg J, Adell R, Svensson B. Temporomandibular joint discectomy for treatment of unilateral internal derangementsa 5-year follow-up evaluation. Int J Oral Maxillofac Surg. 2004;33(1):8-12.

96. Agerberg G, Lundberg M. Changes in the temporomandibular joint after surgical treatment. A radiologic follow-up study. Oral Surg Oral Med Oral Pathol. 1971;32(6):865-75.

97. Hansson LG, Hansson T, Petersson A. A comparison between clinical and radiologic findings in 259 temporomandibular joint patients. J Prosthet Dent. 1983;50(1):89-94.

98. Dimitroulis G. A critical review of interpositional grafts following temporomandibular joint discectomy with an overview of the dermis-fat graft. Int J Oral Maxillofac Surg. 2011;40(6):561-8.

99. Henry CH, Wolford LM. Treatment outcomes for temporomandibular joint reconstruction after Proplast-Teflon implant failure. J Oral Maxillofac Surg. 1993;51(4):352-8.

100. Van Bellinghen X, Idoux-Gillet Y, Pugliano M, Strub M, Bornert $\mathrm{F}$, Clauss $\mathrm{F}$, et al. Temporomandibular joint regenerative medicine. Int J Mol Sci. 2018;19(2):446.

Open Access This chapter is licensed under the terms of the Creative Commons Attribution 4.0 International License (http://creativecommons. org/licenses/by/4.0/), which permits use, sharing, adaptation, distribution and reproduction in any medium or format, as long as you give appropriate credit to the original author(s) and the source, provide a link to the Creative Commons license and indicate if changes were made.

The images or other third party material in this chapter are included in the chapter's Creative Commons license, unless indicated otherwise in a credit line to the material. If material is not included in the chapter's Creative Commons license and your intended use is not permitted by statutory regulation or exceeds the permitted use, you will need to obtain permission directly from the copyright holder. 